\title{
Direct Evidence That Protein Kinase C Plays an Essential Role in the Development of Late Preconditioning against Myocardial Stunning in Conscious Rabbits and That $\epsilon$ Is the Isoform Involved
}

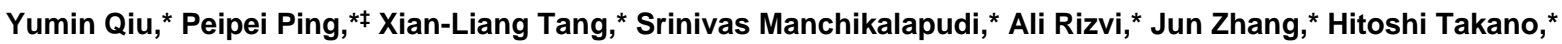 \\ Wen-Jian Wu, ${ }^{*}$ Steffi Teschner, ${ }^{\star}$ and Roberto Bolli ${ }^{\star \neq}$ \\ * Experimental Research Laboratory, Division of Cardiology, and the ${ }^{\ddagger}$ Department of Physiology and Biophysics, University of \\ Louisville, Louisville, Kentucky 40292
}

\begin{abstract}
Brief ischemic episodes confer marked protection against myocardial stunning 1-3 d later (late preconditioning [PC] against stunning). The mechanism of this powerful protective effect is poorly understood. Although protein kinase $\mathrm{C}$ (PKC) has been implicated in PC against infarction, it is unknown whether it triggers late $\mathrm{PC}$ against stunning. In addition, the entire PKC hypothesis of ischemic PC remains controversial, possibly because the effects of PKC inhibitors on $\mathrm{PC}$ protection have not been correlated with their effects on PKC activity and/or translocation in vivo. Thus, conscious rabbits underwent a sequence of six 4-min coronary occlusion $(\mathrm{O}) / 4-\mathrm{min}$ reperfusion $(\mathrm{R})$ cycles for three consecutive days (days 1, 2, and 3). In the control group (group I, $n=7$ ), the recovery of systolic wall thickening after the six $\mathrm{O} / \mathrm{R}$ cycles was markedly improved on days 2 and 3 compared with day 1 , indicating the development of late PC against stunning. Administration of the PKC inhibitor chelerythrine at a dose of $5 \mathrm{mg} / \mathrm{kg}$ before the first $O$ on day 1 (group II, $n=10$ ) abrogated the late PC effect against stunning, whereas a 10 -fold lower dose $(0.5 \mathrm{mg} / \mathrm{kg}$; group III, $n=7$ ) did not. Administration of $5 \mathrm{mg} / \mathrm{kg}$ of chelerythrine 10 min after the sixth reperfusion on day 1 (group IV, $n=$ 6) failed to block late PC against stunning. When rabbits were given $5 \mathrm{mg} / \mathrm{kg}$ of chelerythrine in the absence of $\mathrm{O} / \mathrm{R}$ (group $\mathrm{V}, n=5$ ), the severity of myocardial stunning $24 \mathrm{~h}$ later was not modified. Pretreatment with phorbol 12myristate 13 -acetate $(4 \mu \mathrm{g} / \mathrm{kg})$ on day 1 without ischemia (group VI, $n=11$ ) induced late PC against stunning on day 2 and the magnitude of this effect was equivalent to that observed after ischemic PC. In vehicle-treated rabbits (group VIII, $n=5$ ), the six O/R cycles caused translocation of PKC isoforms $\epsilon$ and $\eta$ from the cytosolic to the particulate frac-
\end{abstract}

Yumin Qiu and Peipei Ping contributed equally to this work.

Part of this work was presented in preliminary form at the American Heart Association meeting in New Orleans, November 1996 and at the International Society for Heart Research meeting in Vancouver, July 1997.

Address correspondence to Roberto Bolli, Division of Cardiology, University of Louisville, Louisville, KY 40292. Phone: 502-8521837; FAX: 502-852-6474; E-mail: rbolli@louisville.edu

Received for publication 21 July 1997 and accepted in revised form 18 February 1998.

J. Clin. Invest.

(C) The American Society for Clinical Investigation, Inc. 0021-9738/98/05/2182/17 \$2.00

Volume 101, Number 10, May 1998, 2182-2198

http://www.jci.org tion without significant changes in total PKC activity, in the subcellular distribution of total PKC activity, or in the subcellular distribution of the $\alpha, \beta_{1}, \beta_{2}, \gamma, \delta, \zeta, \iota, \lambda$, and $\mu$ isoforms. The higher dose of chelerythrine $(5 \mathrm{mg} / \mathrm{kg}$; group $X$, $n=5$ ) prevented the translocation of both PKC $\epsilon$ and $\eta$ induced by ischemic PC, whereas the lower dose $(0.5 \mathrm{mg} / \mathrm{kg}$; group XI, $n=5$ ) prevented the translocation of PKC $\eta$ but not that of $\epsilon$, indicating that the activation of $\epsilon$ is necessary for late PC to occur whereas that of $\eta$ is not. To our knowledge, this is the first demonstration that a PKC inhibitor actually prevents the translocation of PKC induced by ischemic PC in vivo, and that this inhibition of PKC translocation results in loss of $\mathrm{PC}$ protection. Taken together, the results demonstrate that the mechanism of late $\mathrm{PC}$ against myocardial stunning in conscious rabbits involves a PKCmediated signaling pathway, and implicate $\epsilon$ as the specific PKC isoform responsible for the development of this cardioprotective phenomenon. (J. Clin. Invest. 1998. 101:21822198.) Key words: chelerythrine - myocardial ischemia • myocardial reperfusion $\bullet \mathrm{PKC} \epsilon$ isoform $\bullet \mathrm{PKC} \eta$ isoform

\section{Introduction}

The late phase of ischemic preconditioning $(\mathrm{PC})^{1}$ is the phenomenon whereby brief episodes of ischemia increase the tolerance of the myocardium to subsequent ischemic injury 24-72 h later (1-15). Unlike the early phase of PC, which wanes within 2-3 $\mathrm{h}$ after the initial ischemic episode (16), the protective effects of the late phase of PC persist for several days $(6,12)$. The late phase of $\mathrm{PC}$ has been shown to protect against myocardial infarction in dogs (1) and rabbits $(2,3,5,9,12,13,15)$, and against myocardial stunning in pigs $(4,6,7)$ and rabbits $(10,11,14)$. In particular, in conscious rabbits, a sequence of six 4-min coronary occlusions interspersed with 4-min reperfusions significantly attenuates the severity of the stunning caused by the same sequence of coronary occlusions and reperfusions $24-72 \mathrm{~h}$ later, indicating that the myocardium possesses an endogenous protective mechanism that is activated by brief ischemic stresses and that results in a marked protection against myocardial stunning at a distance of 24-72 h (10, $11,14)$. At present, little is known regarding the mechanism(s) that underlies late PC against myocardial stunning.

Several studies $(5,17-33)$ indicate that protein kinase $\mathrm{C}$ (PKC), an ubiquitous intracellular mediator (34), may play an important role in the genesis of ischemic PC. However, no information is currently available as to whether PKC plays a role

1. Abbreviations used in this paper: ECG, electrocardiogram; LV, left ventricular; PC, preconditioning; PKC, protein kinase C; PMA, phorbol 12-myristate 13-acetate; WTh, wall thickening. 
in late PC against myocardial stunning. Although the ischemic PC protocols that elicit delayed protection against stunning cause translocation of the $\epsilon$ and $\eta$ isoforms of PKC in conscious rabbits (8), it is unknown whether this translocation is part of the mechanism of late PC against stunning or is merely an epiphenomenon. Furthermore, assuming that the translocation of PKC $\epsilon$ and $\eta$ is part of the mechanism of late PC, it is unknown whether such mechanism involves both $\epsilon$ and $\eta$ or only one of them and, in the latter case, which one. In addition, intense controversy exists regarding the role of $\mathrm{PKC}$ in the early phase of ischemic $\mathrm{PC}$, as inhibitors of $\mathrm{PKC}$ have failed to block the infarct-limiting effect of PC in canine (35) and porcine $(36,37)$ models, and no association has been found between ischemic PC and translocation of total PKC activity in rabbits (38) and dogs (35).

The overall objective of the present study was to investigate the role of PKC in late PC against myocardial stunning. In addition to using a pharmacological approach similar to that used previously (i.e., administration of PKC inhibitors and activators), we designed this investigation with two specific concerns in mind. First, no previous study has demonstrated that the PKC inhibitors used actually blocked the translocation of individual PKC isoforms induced by ischemic PC in vivo. In principle, it is possible that in some studies PKC inhibitors failed to block PC because of their inability to block the specific PKC isozyme(s) involved in ischemic PC. Accordingly, in the present study $(a)$ we correlated the effects of PKC inhibitors on myocardial stunning with their effects on the subcellular distribution of PKC isoforms, and $(b)$ we tested two different doses of PKC inhibitors to separate the roles of individual PKC isozymes. Second, all of the studies that have assessed the role of PKC in ischemic PC have been performed in anesthestized, open-chest animal models, in which a variety of unphysiological conditions (e.g., anesthesia, surgical trauma, elevated catecholamines, excessive production of free radicals, release of cytokines, fluctuations in temperature, etc. [39, 40]) may obfuscate the role of $\mathrm{PKC}$ in ischemic $\mathrm{PC}$ and/or interfere with the phenomenon of ischemic PC (41-44). Accordingly, the present experiment was conducted in conscious, unsedated rabbits, which are devoid of the potentially confounding interference of the aforementioned factors.

The specific goals of this investigation were: $(a)$ to determine whether administration of chelerythrine (a potent and selective PKC inhibitor) blocks the late phase of ischemic PC against myocardial stunning; $(b)$ to determine whether administration of phorbol 12-myristate 13-acetate (PMA, a general PKC activator) mimics late PC against myocardial stunning; and $(c)$ to determine whether the dose of chelerythrine that blocks late $\mathrm{PC}$ against stunning also blocks the translocation of PKC associated with the PC ischemia and, conversely, whether a lower dose of chelerythrine that fails to block late PC also fails to block PKC translocation. To achieve this latter goal, both the total activity of PKC and the subcellular distribution of all PKC isoforms were examined after ischemic PC in the presence and absence of chelerythrine given at two doses (5 or $0.5 \mathrm{mg} / \mathrm{kg}$ ).

\section{Methods}

This study was performed in accordance with the guidelines of the Animal Care and Use Committee of the University of Louisville
School of Medicine (Louisville, KY) and with the Guide for the Care and Use of Laboratory Animals (Department of Health and Human Services, National Institutes of Health, Publication No. 86-23).

\section{Pilot studies}

Pilot studies were conducted in eight rabbits to identify the optimal dose of PMA and to determine whether doses of chelerythrine of 5 and $0.5 \mathrm{mg} / \mathrm{kg}$ would block PMA-induced hypertension. To avoid any potential confounding effect related to changes in afterload, a dose of PMA was sought that would be effective in mimicking ischemic PC, yet would have no appreciable effect on arterial blood pressure. Arterial pressure was measured by cannulating the ear dorsal artery with a 23-gauge angiocatheter. The catheter was connected to a fluid-filled high-sensitivity pressure transducer, which was connected to a pressure analyzer (model BPA-109; Micro-Med, Louisville, KY). In two rabbits, an intravenous (i.v.) bolus of $20 \mu \mathrm{g} / \mathrm{kg}$ of PMA produced an increase in mean arterial pressure $(+6 \mathrm{mmHg}$ in one rabbit and +18 $\mathrm{mmHg}$ in another rabbit), with no concomitant change in thickening fraction. We therefore tested a lower dose of PMA $(12 \mu \mathrm{g} / \mathrm{kg})$, but found again an increase in mean arterial pressure of 6-7 $\mathrm{mmHg}$. When we decreased the dose of PMA to $4 \mu \mathrm{g} / \mathrm{kg}$, we found that this dose produced no demonstrable alteration in arterial pressure, even when the dose was repeated several times in the same rabbit at 20min intervals. Furthermore, this dose produced no change in systolic thickening fraction. Consequently, this dose was chosen for the present experiments. Pretreatment with $5 \mathrm{mg} / \mathrm{kg}$ of chelerythrine i.v. $5 \mathrm{~min}$ before administration of a pressure-altering dose of PMA $(12 \mu \mathrm{g} / \mathrm{kg})$ completely blocked the rise in mean arterial pressure after PMA. Consequently, this dose of chelerythrine was chosen for the present experiments. A 10-fold lower dose of chelerythrine $(0.5 \mathrm{mg} / \mathrm{kg})$ failed to attenuate the increase in arterial pressure after PMA.

\section{Experimental preparation}

The experimental preparation has been described in detail previously $(10,11,13-15)$ and will be briefly summarized here. New Zealand White male rabbits $(2.2 \pm 0.1 \mathrm{~kg})$ were instrumented under sterile conditions with a balloon occluder around a major branch of the left coronary artery, a 10-MHz pulsed Doppler ultrasonic crystal in the center of the region to be rendered ischemic, and bipolar ECG leads on the chest wall. The chest wound was closed in layers, and a small tube was left in the thorax for $3 \mathrm{~d}$ to evacuate air and fluids postoperatively. Gentamicin was administered before surgery and on the first and second postoperative days $(0.7 \mathrm{mg} / \mathrm{kg}$ intramuscularly each day). Rabbits were allowed to recover for a minimum of $10 \mathrm{~d}$ after surgery.

\section{Experimental protocol}

Throughout the experiments, rabbits were kept in a cage in a quiet, dimly lit room. Left ventricular (LV) systolic wall thickening (WTh), range gate depth, and the ECG were continuously recorded on a thermal array chart recorder (TA6000; Gould Inc., Valley View, $\mathrm{OH})$. No sedative or antiarrhythmic agents were given at any time. The experimental protocol is illustrated in Figs. 1 and 2. The study consisted of two successive phases (A and B).

\section{Phase A: Studies of myocardial stunning}

The goal of phase A was to determine whether pharmacologic inhibition or activation of PKC prevents or mimics late PC against stunning, respectively. The experimental protocol consisted of three consecutive days of coronary artery occlusions (days 1, 2, and 3, respectively; Fig. 1). On each day, the rabbits underwent a sequence of six 4-min coronary occlusions interspersed with 4 min of reperfusion. The performance of successful coronary occlusions was verified by observing the development of ST-segment elevation and changes in the QRS complex on the electrocardiogram (ECG) and the appearance of paradoxical systolic wall thinning on the ultrasonic crystal recordings. Measurements of systolic Wth were obtained before treatment, $1 \mathrm{~min}$ before the first coronary occlusion, $3 \mathrm{~min}$ into each occlusion, $3 \mathrm{~min}$ into each reperfusion period, and 5, 15, and $30 \mathrm{~min}$ and $1,2,3,4$, and $5 \mathrm{~h}$ after the sixth reperfusion. 
Rabbits were assigned to six groups (Fig. 1): group I (controls), group II (chelerythrine $5 \mathrm{mg} / \mathrm{kg}$ ), group III (chelerythrine $0.5 \mathrm{mg} / \mathrm{kg}$ ), group IV (chelerythrine after reperfusion), group V (chelerythrine pretreatment), and group VI (PMA pretreatment). Group I (control rabbits) underwent the coronary occlusion/reperfusion protocol on days 1,2, and 3; on day 1, these animals received vehicle (DMSO plus normal saline) i.v. in volumes equivalent to those administered to groups II, III, IV, V, and VI $(0.5 \mathrm{ml} / \mathrm{kg}$ of DMSO $+0.5 \mathrm{ml} / \mathrm{kg}$ of saline) $5 \mathrm{~min}$ before the first coronary occlusion. On day 1 , rabbits in group II underwent the six coronary occlusion/reperfusion cycles and received an i.v. bolus of chelerythrine $(5 \mathrm{mg} / \mathrm{kg}) 5 \mathrm{~min}$ before the first coronary occlusion. On days 2 and 3, these rabbits underwent the same coronary occlusion/reperfusion protocol without any treatment. Group III underwent the same protocol as group II except that the rabbits received a 10 -fold lower dose of chelerythrine $(0.5 \mathrm{mg} / \mathrm{kg})$. In group IV, rabbits received an i.v. bolus of chelerythrine $(5 \mathrm{mg} / \mathrm{kg}) 10$ min after the sixth reperfusion on day 1 ; on days 2 and 3, these animals underwent the occlusion/reperfusion protocol without any treatment. In group $\mathrm{V}$, rabbits were treated on day 1 with the same dose of chelerythrine as group II $(5 \mathrm{mg} / \mathrm{kg})$ but underwent the coronary oc-
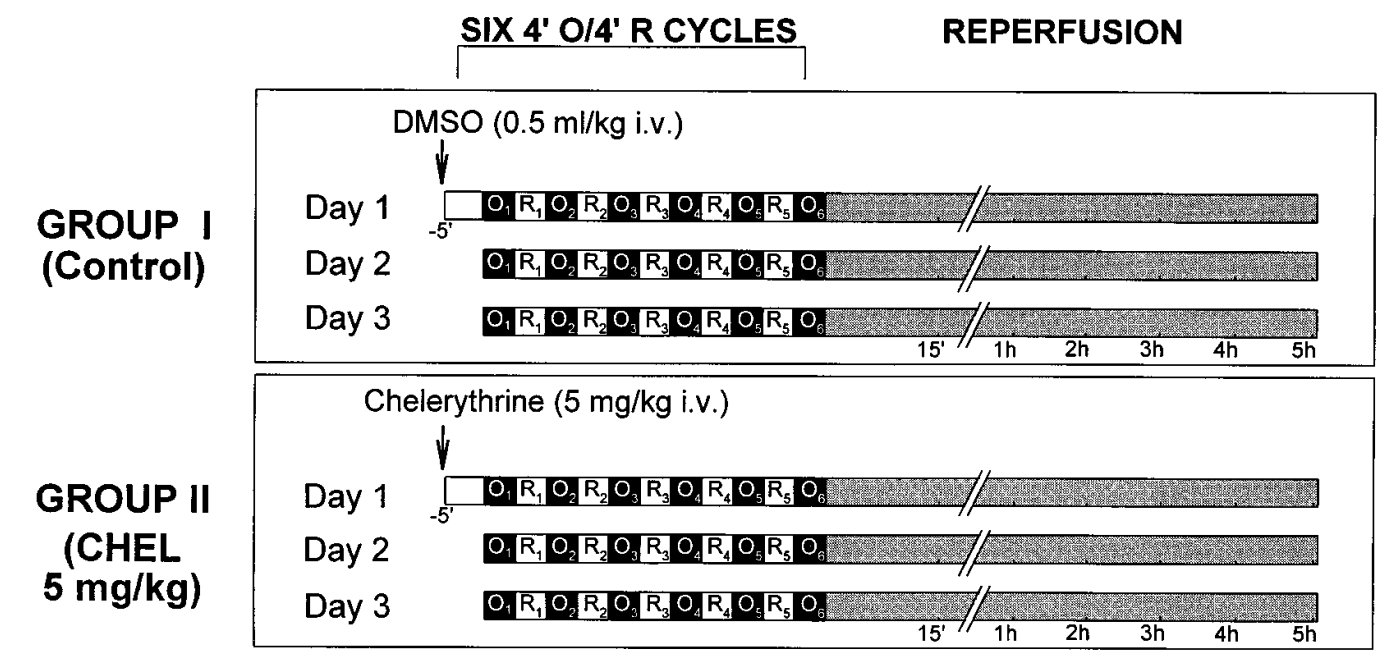

\section{GROUP III (CHEL $0.5 \mathrm{mg} / \mathrm{kg}$ )} GROUP IV
(CHEL after
reperfusion)

GROUP V (CHEL pretreatment)
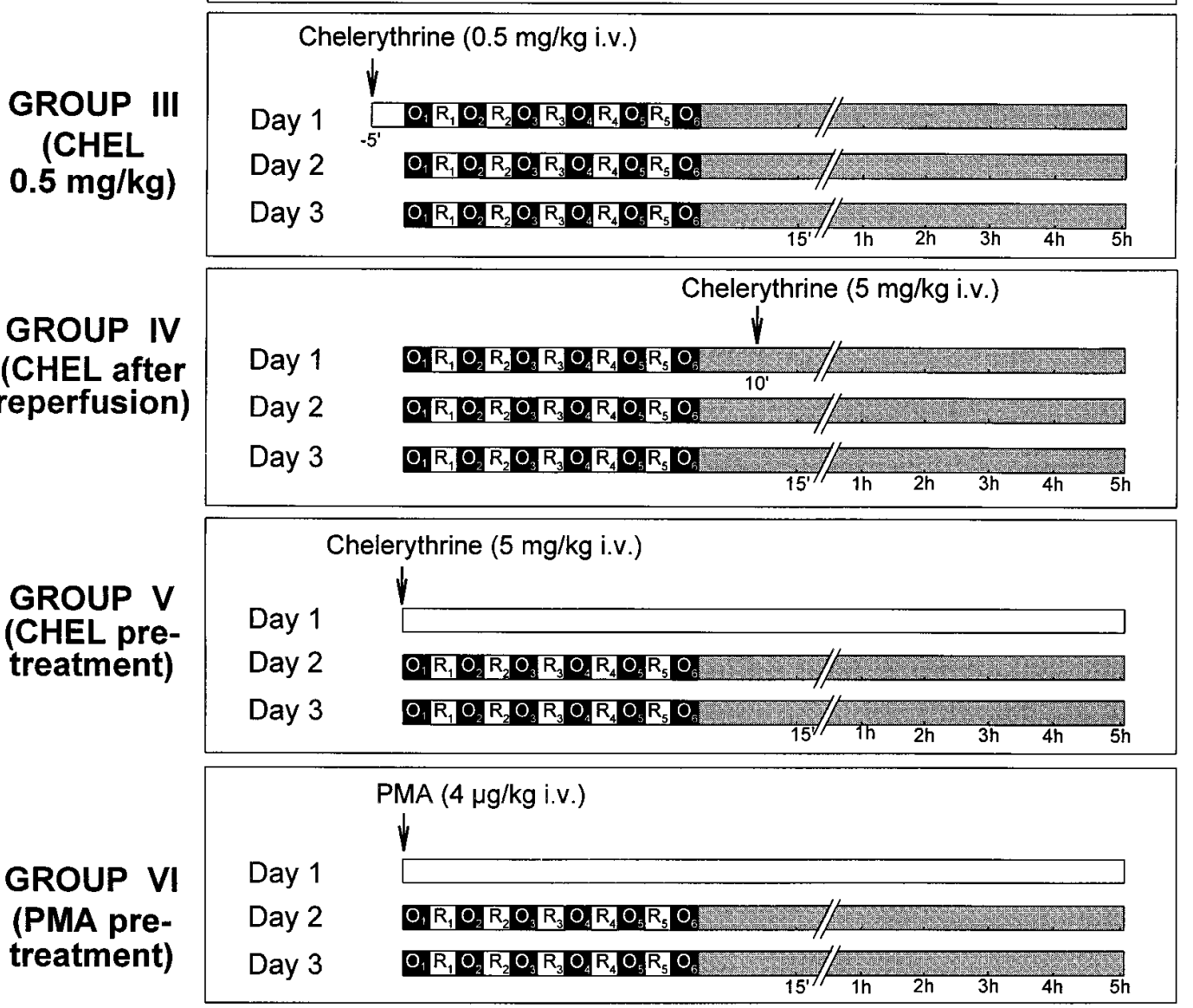

Figure 1. Experimental protocol for phase A. Six groups of rabbits were studied. All groups underwent a sequence of six 4-min coronary occlusion/ 4-min reperfusion cycles followed by a 5 -h observation period. On day 1 , rabbits in group I ( $n=7$, control group) received an i.v. bolus of DMSO $(0.5 \mathrm{ml} / \mathrm{kg})$ and normal saline $(0.5 \mathrm{ml} / \mathrm{kg}) 5 \mathrm{~min}$ before the first coronary occlusion (this was the same volume of vehicle administered to the other five groups). On day 1 , rabbits in group II ( $n=10$, chelerythrine $5 \mathrm{mg} / \mathrm{kg}$ ) received an i.v. bolus of chelerythrine $(5 \mathrm{mg} / \mathrm{kg}) 5 \mathrm{~min}$ before the first coronary occlusion. On day 1 , rabbits in group III ( $n=7$, chelerythrine $0.5 \mathrm{mg} / \mathrm{kg}$ ) received an i.v. bolus of chelerythrine $(0.5 \mathrm{mg} / \mathrm{kg})$ 5 min before the first coronary occlusion. On day 1 , rabbits in group IV ( $n=6$, chelerythrine after reperfusion) received an i.v. bolus of chelerythrine $(5 \mathrm{mg} / \mathrm{kg}) 10 \mathrm{~min}$ after the sixth reperfusion. On days 2 and 3 , all four groups (groups I-IV) underwent the six 4-min coronary occlusion/reperfusion protocol without any treatment. On day 1 , rabbits in group $\mathrm{V}(n=5$, chelerythrine pretreatment) received an i.v. bolus of chelerythrine $(5 \mathrm{mg} / \mathrm{kg}$ ) but did not undergo coronary occlusion; these animals were then subjected to the occlusion/reperfusion protocol on days 2 and 3. On day 1, rabbits in group VI ( $n=11$, PMA pretreatment) received an i.v. bolus of PMA ( $4 \mu \mathrm{g} / \mathrm{kg})$ but did not undergo coronary occlusion; these animals were then subjected to the occlusion/reperfusion protocol on days 2 and 3 . 


\section{GROUP VII (DMSO control)}

\section{GROUP VIII (PC+ DMSO)}

\section{GROUP IX (CHEL control)}

\section{GROUP $X$ (PC+ CHEL $5 \mathrm{mg} / \mathrm{kg}$ )}

\section{GROUP XI (PC+ CHEL $0.5 \mathrm{mg} / \mathrm{kg}$ )}

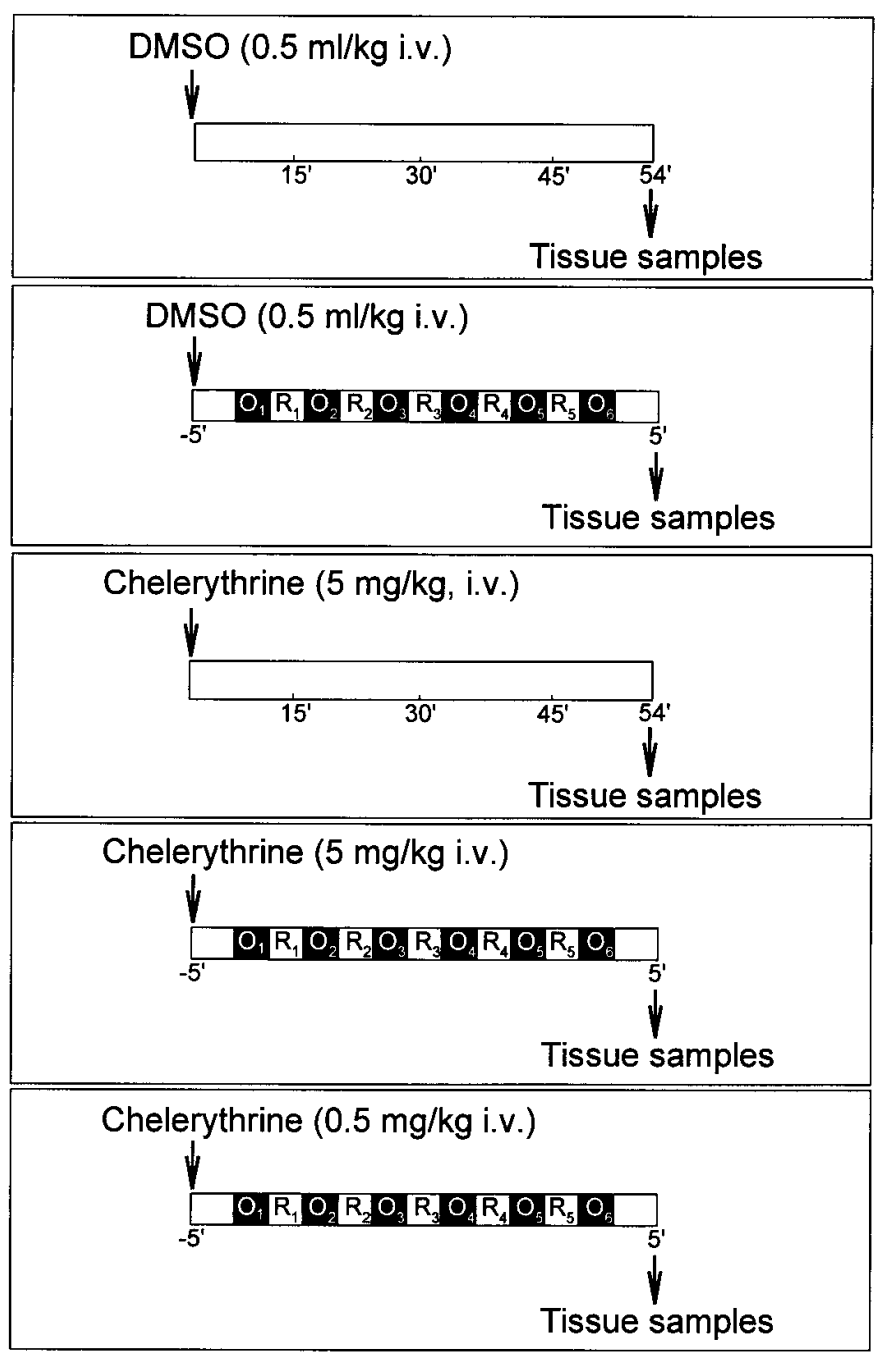

Figure 2. Experimental protocol for phase B. Five groups of rabbits were studied. Rabbits in group VII ( $n=5$, control group) received vehicle (DMSO $0.5 \mathrm{ml} / \mathrm{kg}+$ normal saline $0.5 \mathrm{ml} / \mathrm{kg}$ ) without coronary occlusion/reperfusion and were killed $54 \mathrm{~min}$ later. Rabbits in group VIII $(n=5$, PC without chelerythrine) underwent the six 4-min occlusion/4-min reperfusion cycles and received vehicle (DMSO + normal saline) $5 \mathrm{~min}$ before the first occlusion. Rabbits in group IX ( $n=5$, chelerythrine $5 \mathrm{mg}$ / $\mathrm{kg}$ without $\mathrm{PC}$ ) received chelerythrine $(5 \mathrm{mg} / \mathrm{kg})$ without coronary occlusion and were killed 54 min later. Rabbits in group $\mathrm{X}(n=5, \mathrm{PC}$ with chelerythrine $5 \mathrm{mg} / \mathrm{kg})$ underwent the six coronary occlusion/reperfusion cycles and received chelerythrine $(5 \mathrm{mg} / \mathrm{kg}) 5 \mathrm{~min}$ before the first occlusion. Rabbits in group XI ( $n=5$, PC with chelerythrine $0.5 \mathrm{mg} / \mathrm{kg}$ ) underwent the six occlusion/reperfusion cycles and received chelerythrine $(0.5 \mathrm{mg} / \mathrm{kg}) 5 \mathrm{~min}$ before the first occlusion. Rabbits in groups VIII, X, and XI were killed 5 min after the last reperfusion. clusion/reperfusion protocol only on days 2 and 3. In group VI, rabbits received on day 1 an i.v. bolus of PMA $(4 \mu \mathrm{g} / \mathrm{kg}$ dissolved in 0.5 $\mathrm{ml} / \mathrm{kg}$ of DMSO and $0.5 \mathrm{ml} / \mathrm{kg}$ of normal saline) but did not undergo coronary occlusion; these animals were then subjected to the coronary occlusion/reperfusion protocol on days 2 and 3. Chelerythrine chloride (Research Biochemicals International, Natick, MA) was dissolved in $0.5 \mathrm{ml} / \mathrm{kg}$ of DMSO and $0.5 \mathrm{ml} / \mathrm{kg}$ of normal saline (total volume infused, $1 \mathrm{ml} / \mathrm{kg}$ ). All solutions (chelerythrine, PMA, vehicle) were filtered through a $0.2 \mu \mathrm{m}$ Millipore filter to ensure sterility.

Measurement of regional myocardial function. Regional myocardial function was assessed as systolic thickening fraction using the pulsed Doppler probe, as previously described (10). Percent systolic thickening fraction was calculated as the ratio of net systolic thickening to end-diastolic wall thickness, multiplied by 100 (10). The total deficit of systolic WTh after reperfusion (an integrative assessment of the overall severity of myocardial stunning after the sixth reperfusion) was calculated by measuring the area comprised between the systolic WTh versus time line and the baseline ( $100 \%$ line) during the 5-h recovery phase after the sixth reperfusion $(4,6,7,10,11,14)$. In all animals, measurements were averaged from at least 10 beats at baseline, and from at least 5 beats at all subsequent time points.

Postmortem tissue analysis. At the conclusion of the study, the rabbits were given heparin (1,000 U i.v.), after which they were anesthetized with sodium pentobarbital $(50 \mathrm{mg} / \mathrm{kg}$ i.v.) and killed with $\mathrm{KCl}$. The heart was excised and the size of the occluded-reperfused coronary vascular bed was determined by tying the coronary artery at the site of the previous occlusion and by perfusing the aortic root for 2 min with a $5 \%$ solution of Phthalo blue dye in normal saline at a pressure of $70 \mathrm{mmHg}$ using a Langendorff apparatus. The heart was then cut into 6-7 transverse slices, which were incubated for $10 \mathrm{~min}$ at $37^{\circ} \mathrm{C}$ in a $1 \%$ solution of triphenyltetrazolium chloride in phosphate buffer ( $\mathrm{pH}$ 7.4) to verify the absence of infarction. The portion of the left ventricle supplied by the previously occluded coronary artery (occluded bed) was identified by the absence of blue dye and separated from the rest of the left ventricle. Both components were weighed to determine the occluded bed size as a percentage of total LV weight.

\section{Phase B: Studies of PKC activity and subcellular distribution}

Having observed that chelerythrine blocks late PC against stunning at $5 \mathrm{mg} / \mathrm{kg}$ but not at $0.5 \mathrm{mg} / \mathrm{kg}$, in phase B we sought to determine whether the doses of chelerythrine used in phase A inhibit translocation of PKC isoforms $\epsilon$ and $\eta$, which we have previously found to be associated with PC in this rabbit model (8). Rabbits were assigned to five groups (Fig. 2): group VII (controls), group VIII (PC without chelerythrine), group IX (chelerythrine without PC), group X (PC with chelerythrine $5 \mathrm{mg} / \mathrm{kg}$ ), and group XI (PC with chelerythrine 0.5 $\mathrm{mg} / \mathrm{kg}$ ). Group VII (control rabbits) did not undergo coronary occlusion and was given vehicle (DMSO plus normal saline) i.v. in volumes equivalent to those administered to the other four groups $(0.5 \mathrm{ml} / \mathrm{kg}$ of DMSO $+0.5 \mathrm{ml} / \mathrm{kg}$ of saline). The rabbits were killed 54 min after 
the administration of vehicle (time interval corresponding to the interval elapsed between treatment and time of death in groups IX, X, and XI). The heart was immediately excised, and myocardial samples $(\sim 0.5 \mathrm{~g})$ were rapidly removed from the anterior LV wall and stored in liquid nitrogen until used. Groups VIII, X, and XI underwent the sequence of six 4-min coronary occlusion/4-min reperfusion cycles as in phase $\mathrm{A}$; in groups $\mathrm{X}$ and $\mathrm{XI}$, chelerythrine was given as in groups II and III of phase A, respectively ( 5 and $0.5 \mathrm{mg} / \mathrm{kg}$, respectively, as an i.v. bolus 5 min before the first occlusion), whereas group VIII received equivalent volumes of vehicle $(0.5 \mathrm{ml} / \mathrm{kg}$ of DMSO + $0.5 \mathrm{ml} / \mathrm{kg}$ of normal saline). In all three groups, rabbits were killed 5 min after the last reperfusion. The heart was immediately excised and myocardial samples $(\sim 0.5 \mathrm{~g})$ were rapidly removed from the ischemic-reperfused region (whose boundaries had been marked with sutures at the time of instrumentation). In group IX, rabbits received chelerythrine as in groups X and XI but did not undergo coronary occlusion/reperfusion; these animals were killed 54 min after the administration of chelerythrine (time interval corresponding to the interval elapsed between treatment and killing in groups $\mathrm{X}$ and $\mathrm{XI}$ ) and tissue samples were obtained as described above. Thus, the treatment protocol used in group VIII in phase B was identical to that used in group I in phase $\mathrm{A}$, whereas the treatment protocols used in groups IX, X, and XI in phase B were identical to those used in groups V, II, and III, respectively, in phase A (Figs. 1 and 2).

Tissue sample preparation. Frozen myocardial tissue samples were powdered in a prechilled stainless steel mortar and pestle. Total cellular proteins were obtained by glass-glass homogenization of the powdered tissue in sample buffer containing $50 \mathrm{mmol} / \mathrm{liter}$ Tris-HCI (pH 7.5), 5 mmol/liter EDTA, $10 \mathrm{mmol} /$ liter EGTA, $10 \mathrm{mmol} / \mathrm{liter}$ benzamidine, $50 \mu \mathrm{g} / \mathrm{ml}$ PMSF, $10 \mu \mathrm{g} / \mathrm{ml}$ aprotinin, $10 \mu \mathrm{g} / \mathrm{ml}$ leupeptin, $10 \mu \mathrm{g} / \mathrm{ml}$ pepstatin A, and $0.3 \% \beta$-mercaptoethanol (8). The cytosolic and particulate portions of total cellular proteins were separated by a 30-min centrifugation at 45,000 $\mathrm{g}$. Protein concentration was determined by the method of Bradford (Biorad Laboratories, Hercules, CA). The yields of total cellular proteins, cytosolic proteins, and particulate proteins were carefully recorded for each tissue sample tested. To ensure the most accurate assessment of PKC protein expression and to avoid any decay in PKC phosphorylation activity,
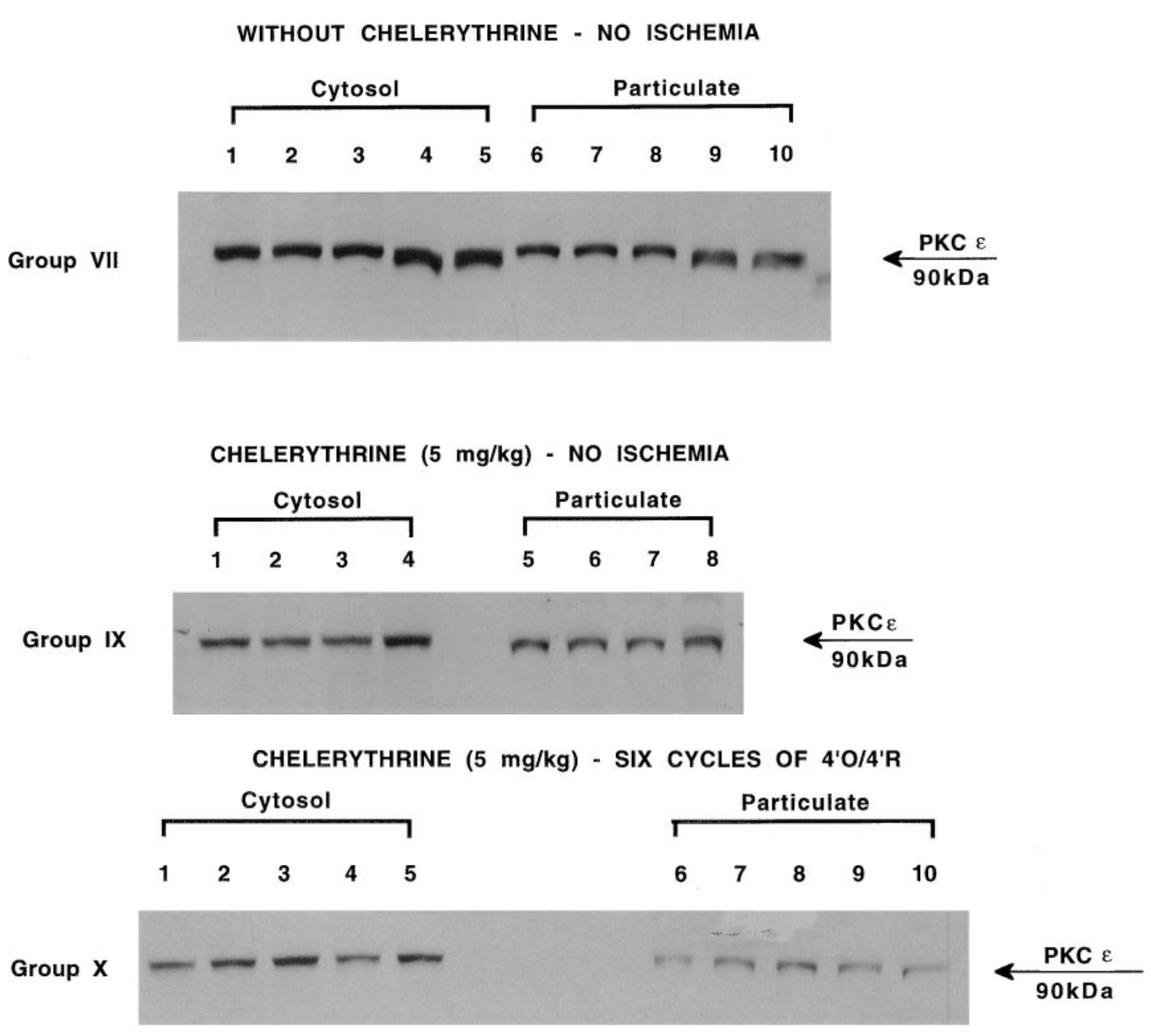

Figure 3. Western immunoblot showing the subcellular distribution of PKC $\epsilon$ in five rabbits in group VII, which did not undergo coronary occlusion and did not receive chelerythrine (top), in four rabbits in group IX, which received chelerythrine $5 \mathrm{mg} / \mathrm{kg}$ without undergoing coronary occlusion (top), in five rabbits in group $\mathrm{X}$, which received chelerythrine $5 \mathrm{mg} / \mathrm{kg}$ $5 \mathrm{~min}$ before six cycles of $4-\mathrm{min}$ coronary occlusion $(O) / 4$-min reperfusion $(R ;$ bottom $)$, and in five rabbits in group XI, which received chelerythrine at 10 -fold lower dose $(0.5 \mathrm{mg} / \mathrm{kg})$ $5 \mathrm{~min}$ before the six 4-min O/R cycles (bottom). (One of the five rabbits in group IX was not examined by Western immunoblotting due to technical problems.) Note that in the absence of ischemia (groups VII and IX), most of the $\epsilon$ protein was in the cytosolic fraction, and that this pattern remained unchanged after six cycles of coronary occlusion/reperfusion in groups $\mathrm{X}$ and $\mathrm{XI}$, indicating that both doses of chelerythrine ( 5 and $0.5 \mathrm{mg} / \mathrm{kg}$ ) failed to block ischemic PCinduced translocation of PKC $\epsilon$. 
protein samples were processed by either Western immunoblotting or phosphorylation assays immediately after tissue sample preparation.

PKC Western immunoblotting analysis. Assessment of PKC isoforms was conducted using standard SDS-PAGE Western immunoblotting techniques (8). Briefly, $100 \mu \mathrm{g}$ of proteins derived from the homogenate or from the cytosolic fraction or the particulate fraction of the homogenate was electrophoresed on a $10 \%$ denaturing gel for 4-6 h at $30 \mathrm{~mA}$ per gel. Proteins were electroblotted onto nitrocellulose membranes (Amersham Corp., Arlington Heights, IL). Gel transfer efficiency was carefully recorded by making photocopies of membranes dyed with reversible Ponceau staining and gel retention was determined by Coomassie blue staining (8). Adequate background blocking was accomplished by incubating the nitrocellulose membranes with $5 \%$ nonfat dry milk in Tris buffer saline (TBS). Antibodies against PKC isoforms $\alpha, \beta, \gamma, \epsilon, \zeta, \iota, \lambda, \mu$ (Transduction Laboratories, Lexington, KY), and $\eta$ and $\delta$ (Santa Cruz Biotechnology, Santa Cruz, CA) were used to assess the expression of each individual PKC isoform. The PKC immunoblots were developed with the use of a chemiluminescent system (ECL kit; Amersham Corp.). Each PKC isoform was identified by its specific protein molecular weight and the comigrating signal of a positive control for that isoform. Proteins collected from cell lysates of either Jurkat, HeLa, or macrophage cell lines (Cell Lines and Hybridomas; American Type Culture Collection, Rockville, MD) served as positive controls. The specificity of the PKC antibody binding was confirmed by the use of recombinant PKC isoform peptides (8).

The PKC signals detected by immunoblotting and the corresponding records of Ponceau stains of nitrocellulose membranes were quantitated using an image scanning densitometer (Personal PI; Molecular Dynamics, Sunnyvale, CA). To assure consistency in the data analysis, $100 \mu \mathrm{g}$ of the cytosolic and particulate fractions of all five tissue samples in each group were run on the same gel (Fig. 3). Each immunoblotting experiment was repeated twice and the results were averaged.

Measurement of PKC activity. PKC activity was quantitated using a PKC enzyme assay system (Amersham Corp.) (8). Briefly, we have previously found $25 \mu \mathrm{g}$ of proteins to be the optimal sample dose for the assessment of myocardial PKC activity (8). Consequently, $25 \mu \mathrm{g}$ of proteins from either the cytosolic or the particulate fraction was incubated with $0.2 \mu \mathrm{Ci}$ of $\left[\gamma_{-}{ }^{32} \mathrm{P}\right] \mathrm{ATP}, 0.1 \mathrm{mmol} / \mathrm{liter}$ ATP, $2.3 \mathrm{mmol} /$ liter Hepes, $5.5 \mathrm{mmol} /$ liter $\mathrm{MgCl}_{2}, 28.8 \mu \mathrm{g} / \mathrm{ml} \mathrm{L}-\alpha$-phosphatidyl-L-serine, $2.9 \mathrm{mmol} /$ liter dithiothreitol, $86.5 \mu \mathrm{mol} /$ liter substrate peptide (VRKRTLRRL), and $600 \mu \mathrm{g} / \mathrm{ml}$ lysine-rich histone type IIIS in $50 \mathrm{mmol} /$ liter Tris-HCI buffer $(\mathrm{pH} \mathrm{7.5)}$ for $15 \mathrm{~min}$ at $37^{\circ} \mathrm{C}$. To assess total PKC activity (calcium-stimulated + calciumindependent), $1.15 \mathrm{mmol} /$ liter calcium acetate and $2.3 \mu \mathrm{g} / \mathrm{ml}$ PMA were added to the above buffer. To assess the calcium-independent PKC activity, $2.3 \mu \mathrm{g} / \mathrm{ml}$ PMA and $1 \mathrm{mmol} /$ liter EGTA were added to the above buffer. All reactions were terminated by the addition of stop solution (containing $300 \mathrm{mmol} /$ liter orthophosphoric acid). The phosphorylated substrates were transferred to binding paper, washed in $5 \%$ acetic acid, and counted with a $\beta$ scintillation counter. Washing conditions were optimized to achieve low nonspecific counts $(<5 \%$ of total counts). PKC activity was calculated from the specific counts (total minus nonspecific). Each sample was assayed in triplicate. Data were expressed as pmol of phosphate transferred per minute per milligram of sample proteins.

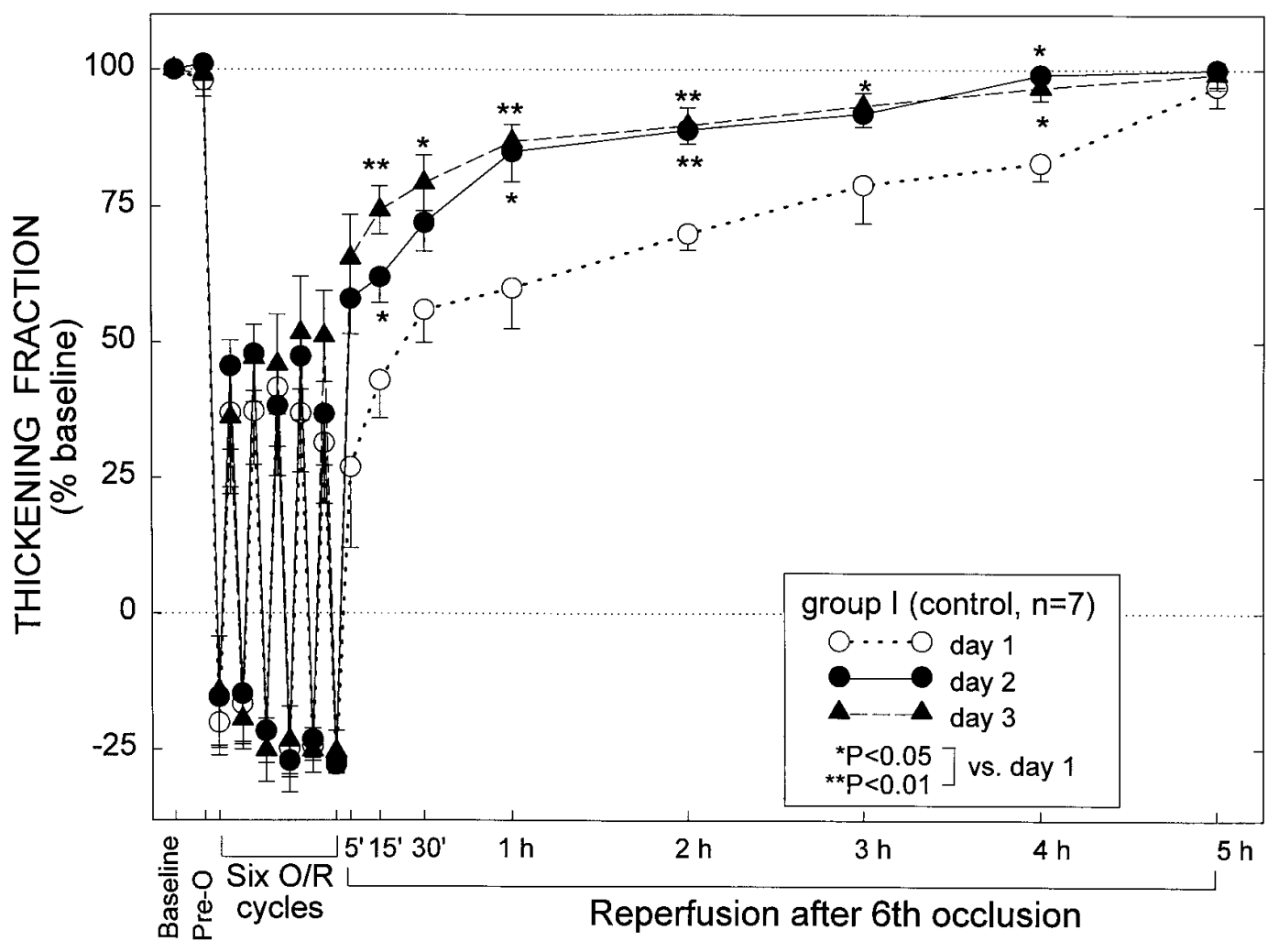

Figure 4. Systolic thickening fraction in the ischemic-reperfused region in the control group (group I) before administration of vehicle $(0.5 \mathrm{ml} /$ $\mathrm{kg}$ DMSO + $0.5 \mathrm{ml} / \mathrm{kg}$ normal saline; baseline), 4 min after the infusion of vehicle (immediately before the first occlusion; preocclusion [Pre-O]), 3 min into each coronary occlusion $(O), 3$ min into each reperfusion $(R)$, and at selected times during the 5-h reperfusion interval after the sixth occlusion. Measurements taken on day 1 are represented by the dashed line with open circles, measurements taken on day 2 are represented by the continuous line with solid circles, and measurements taken on day 3 are represented by the interrupted line with solid triangles $(n=7$ for all three days). Thickening fraction is expressed as a percentage of baseline values. Data are means \pm SEM. 


\section{Statistical analysis}

Data are reported as means \pm SEM. In phase A, intragroup comparisons of hemodynamic variables and WTh were performed by a twoway repeated-measures ANOVA (time and day) to determine whether there was a main effect of time, a main effect of day, or a day-by-time interaction. If the global tests showed a significant main effect or interaction, post hoc contrasts between different time points on the same day or between different days at the same time point were performed with Student's $t$ tests for paired data, and the resulting $P$ values were adjusted according to the Bonferroni correction. For intergroup comparisons, continuous variables were analyzed by either a one-way or a two-way repeated-measures (time and group) ANOVA, as appropriate, followed by unpaired Student's $t$ tests with the Bonferroni correction. In phase B, differences among the five groups with respect to PKC activity, subcellular distribution of total PKC activity, subcellular distribution of PKC $\epsilon$ and $\eta$ isoforms, and translocation of PKC $\epsilon$ and $\eta$ isoforms were analyzed using a one-way ANOVA. If the ANOVA showed an overall difference, post hoc contrasts between two groups were performed with Student's $t$ tests for unpaired data, and the resulting $P$ values were adjusted according to the Bonferroni correction. All statistical analyses were performed using the SAS software system. Two-way ANOVA was performed using the procedure GLM (General Linear Models).

\section{Results}

92 conscious rabbits were used in this study.

\section{Phase A: Studies of myocardial stunning}

Exclusions. 65 conscious rabbits were used for phase A ( 8 for the dose-response studies and 57 for the studies of late PC). Of the 57 rabbits instrumented for the studies of late PC, 9 were assigned to group I (control group), 14 to group II (chelerythrine $5 \mathrm{mg} / \mathrm{kg}$ ), 7 to group III (chelerythrine $0.5 \mathrm{mg} / \mathrm{kg}$ ), 7 to group IV (chelerythrine after reperfusion), 7 to group V (chelerythrine-pretreated group), and 13 to group VI (PMA-pretreated group). Of the nine rabbits assigned to group I, one died of ventricular fibrillation during the fourth occlusion on day 1 and another one during the fifth occlusion on day 2. Of

Table I. Heart Rate (beats/min) during Coronary Occlusion and Reperfusion

\begin{tabular}{|c|c|c|c|c|c|c|c|c|c|c|}
\hline & \multirow[b]{2}{*}{ Baseline } & \multirow[b]{2}{*}{ Preocclusion } & \multirow{2}{*}{$\begin{array}{c}1 \mathrm{st} \\
\text { Occlusion }\end{array}$} & \multirow{2}{*}{$\begin{array}{c}\text { 6th } \\
\text { Occlusion }\end{array}$} & \multicolumn{6}{|c|}{ Reperfusion } \\
\hline & & & & & $30 \mathrm{~min}$ & $1 \mathrm{~h}$ & $2 \mathrm{~h}$ & $3 \mathrm{~h}$ & $4 \mathrm{~h}$ & $5 \mathrm{~h}$ \\
\hline \multicolumn{11}{|c|}{ Group I (control) } \\
\hline Day 1 & $241 \pm 10$ & $241 \pm 10$ & $255 \pm 8$ & $259 \pm 9$ & $228 \pm 9$ & $235 \pm 9$ & $238 \pm 8$ & $241 \pm 8$ & $237 \pm 7$ & $238 \pm 9$ \\
\hline Day 2 & $252 \pm 8$ & $252 \pm 8$ & $251 \pm 7$ & $250 \pm 9$ & $242 \pm 9$ & $242 \pm 8$ & $248 \pm 9$ & $234 \pm 9$ & $227 \pm 8$ & $234 \pm 9$ \\
\hline Day 3 & $238 \pm 9$ & $238 \pm 9$ & $243 \pm 8$ & $251 \pm 7$ & $246 \pm 10$ & $245 \pm 9$ & $243 \pm 8$ & $232 \pm 7$ & $229 \pm 7$ & $230 \pm 8$ \\
\hline \multicolumn{11}{|c|}{ Group II (Chelerythrine 5 mg/kg) } \\
\hline Day 1 & $254 \pm 10$ & $241 \pm 10$ & $238 \pm 9$ & $232 \pm 17$ & $238 \pm 9$ & $237 \pm 7$ & $243 \pm 8$ & $234 \pm 9$ & $241 \pm 8$ & $234 \pm 8$ \\
\hline Day 2 & $242 \pm 17$ & $242 \pm 17$ & $251 \pm 7$ & $244 \pm 9$ & $235 \pm 9$ & $236 \pm 9$ & $234 \pm 9$ & $225 \pm 14$ & $230 \pm 8$ & $227 \pm 7$ \\
\hline Day 3 & $237 \pm 9$ & $237 \pm 9$ & $244 \pm 7$ & $241 \pm 9$ & $236 \pm 11$ & $233 \pm 11$ & $236 \pm 11$ & $238 \pm 11$ & $237 \pm 9$ & $227 \pm 8$ \\
\hline \multicolumn{11}{|c|}{ Group III (Chelerythrine 0.5 mg/kg) } \\
\hline Day 1 & $250 \pm 12$ & $243 \pm 10$ & $236 \pm 11$ & $225 \pm 12$ & $232 \pm 15$ & $226 \pm 12$ & $235 \pm 14$ & $236 \pm 16$ & $244 \pm 17$ & $245 \pm 13$ \\
\hline Day 2 & $265 \pm 10$ & $265 \pm 10$ & $261 \pm 14$ & $252 \pm 14$ & $234 \pm 9$ & $239 \pm 12$ & $240 \pm 14$ & $237 \pm 11$ & $246 \pm 11$ & $237 \pm 16$ \\
\hline Day 3 & $242 \pm 9$ & $242 \pm 9$ & $260 \pm 11$ & $255 \pm 11$ & $250 \pm 7$ & $251 \pm 12$ & $248 \pm 11$ & $240 \pm 9$ & $229 \pm 7$ & $233 \pm 14$ \\
\hline \multicolumn{11}{|c|}{ Group IV (Chelerythrine after reperfusion) } \\
\hline Day 1 & $269 \pm 9$ & $269 \pm 9$ & $268 \pm 12$ & $243 \pm 13$ & $221 \pm 14$ & $219 \pm 11$ & $215 \pm 6$ & $210 \pm 7$ & $225 \pm 11$ & $227 \pm 10$ \\
\hline Day 2 & $270 \pm 10$ & $270 \pm 10$ & $273 \pm 10$ & $254 \pm 11$ & $240 \pm 6$ & $250 \pm 8$ & $249 \pm 9$ & $250 \pm 11$ & $237 \pm 11$ & $234 \pm 11$ \\
\hline Day 3 & $263 \pm 6$ & $263 \pm 6$ & $264 \pm 7$ & $244 \pm 7$ & $239 \pm 6$ & $233 \pm 8$ & $240 \pm 12$ & $233 \pm 8$ & $238 \pm 11$ & $233 \pm 9$ \\
\hline \multicolumn{11}{|c|}{ Group V (Chelerythrine pretreatment) } \\
\hline *Day 1 & $258 \pm 18$ & - & - & - & $234 \pm 16^{*}$ & $237 \pm 17 *$ & $236 \pm 17 *$ & $244 \pm 14^{*}$ & $241 \pm 17 *$ & $238 \pm 16^{*}$ \\
\hline Day 2 & $234 \pm 17$ & $234 \pm 17$ & $245 \pm 11$ & $248 \pm 11$ & $235 \pm 10$ & $241 \pm 13$ & $244 \pm 14$ & $236 \pm 10$ & $235 \pm 18$ & $251 \pm 10$ \\
\hline Day 3 & $256 \pm 10$ & $256 \pm 10$ & $251 \pm 11$ & $246 \pm 12$ & $245 \pm 5$ & $238 \pm 10$ & $243 \pm 8$ & $248 \pm 9$ & $237 \pm 17$ & $256 \pm 17$ \\
\hline \multicolumn{11}{|c|}{ Group VI (PMA treatment) } \\
\hline *Day 1 & $244 \pm 7$ & - & - & - & $243 \pm 12 *$ & $245 \pm 10^{*}$ & $241 \pm 11 *$ & $242 \pm 14 *$ & $251 \pm 14^{*}$ & $234 \pm 11 *$ \\
\hline Day 2 & $254 \pm 8$ & $254 \pm 8$ & $244 \pm 7$ & $237 \pm 9$ & $234 \pm 9$ & $234 \pm 11$ & $238 \pm 9$ & $244 \pm 11$ & $230 \pm 8$ & $232 \pm 10$ \\
\hline Day 3 & $244 \pm 7$ & $244 \pm 7$ & $246 \pm 12$ & $238 \pm 9$ & $225 \pm 10$ & $233 \pm 11$ & $237 \pm 9$ & $236 \pm 7$ & $242 \pm 9$ & $234 \pm 11$ \\
\hline
\end{tabular}

Rabbits were subjected to a sequence of six cycles of 4-min coronary occlusion/4-min coronary reperfusion followed by a 5-h observation period. On day 1, rabbits in group I (control group, $n=7$ ) received an i.v. bolus of vehicle (DMSO $0.5 \mathrm{ml} / \mathrm{kg}$ + normal saline $0.5 \mathrm{ml} / \mathrm{kg}$ ) $5 \mathrm{~min}$ before the first occlusion; rabbits in group II (chelerythrine treatment $5 \mathrm{mg} / \mathrm{kg}, n=10)$ received an i.v. bolus of chelerythrine $(5 \mathrm{mg} / \mathrm{kg}) 5 \mathrm{~min}$ before the first occlusion; rabbits in group III (chelerythrine treatment $0.5 \mathrm{mg} / \mathrm{kg}, n=7)$ received an i.v. bolus of chelerythrine $(0.5 \mathrm{mg} / \mathrm{kg}) 5 \mathrm{~min}$ before the first occlusion; rabbits in group IV (chelerythrine during reperfusion, $n=6)$ received an i.v. bolus of chelerythrine $(5 \mathrm{mg} / \mathrm{kg}) 10 \mathrm{~min}$ after the sixth reperfusion; rabbits in group $\mathrm{V}$ (chelerythrine pretreatment, $n=5$ ) received an i.v. bolus of chelerythrine as in group II, but did not undergo coronary occlusion/reperfusion; rabbits in group IV (PMA pretreatment) received an i.v. bolus of PMA $(4 \mu \mathrm{g} / \mathrm{kg}$ ), but did not undergo coronary occusion/reperfusion. Heart rate was measured before treatment (baseline), 4 min after treatment (preocclusion), at 3 min into the first coronary occlusion, at 3 min into the sixth coronary occlusion, and at selected times after the sixth reperfusion. Data are means \pm SEM.

*On day 1, this group did not undergo the coronary occlusion/reperfusion protocol; heart rate was measured at 90 min, 2,3,4, and $5 \mathrm{~h}$ after chelerythrine or PMA administration, which correspond approximately to 1,3, and $5 \mathrm{~h}$ after the sixth reperfusion in the occlusion/reperfusion protocol. 
the 14 rabbits assigned to group II, three succumbed to ventricular fibrillation (one during the second occlusion on day 1 and two during the fourth occlusion on day 1); another rabbit was excluded because of malfunction of the WTh probe on day 2. Of the seven rabbits assigned to group IV, one was excluded because of malfunction of the balloon occluder on day 1 . Of the seven rabbits assigned to group $\mathrm{V}$, two died on day 1 immediately after administration of chelerythrine. Of the 13 rabbits assigned to group VI, one died of ventricular fibrillation during the fifth occlusion on day 2 and one was excluded because of malfunction of the WTh probe on day 3 . Therefore, 7 rabbits completed days 1, 2, and 3 in group I, 10 in group II, 7 in group III, 6 in group IV, 5 in group V, and 11 in group VI.

Postmortem analysis. The size of the occluded-reperfused vascular bed was similar in the six groups: $1.0 \pm 0.1 \mathrm{~g}(15.6 \pm$ $1.8 \%$ of LV weight) in group I, $1.2 \pm 0.2 \mathrm{~g}(19.0 \pm 1.7 \%)$ in group II, $0.9 \pm 0.1 \mathrm{~g}(16.8 \pm 2.2 \%)$ in group III, $0.9 \pm 0.1 \mathrm{~g}(18.2 \pm$ $2.1 \%)$ in group IV, $1.1 \pm 0.1 \mathrm{~g}(21.0 \pm 1.1 \%)$ in group $\mathrm{V}$, and $1.2 \pm 0.1 \mathrm{~g}(20.0 \pm 2.7 \%)$ in group VI. Tissue staining with triphenyltetrazolium chloride demonstrated absence of infarction in all of the rabbits included in the final analysis, confirming that the injury associated with the six 4-min occlusion/ 4-min reperfusion cycles was completely reversible.

Regional myocardial function. As shown in Table I, there were no significant differences in heart rate among the six groups either during the sequence of coronary occlusion/reperfusion cycles or during the 5-h reperfusion period. Neither chelerythrine nor PMA caused appreciable changes in heart rate. Baseline systolic thickening fraction in the region to be rendered ischemic was $36.4 \pm 4.6 \%, 42.2 \pm 5.4 \%$, and $38.9 \pm 6.4 \%$ on days 1,2 , and 3, respectively, in group I; 32.4 $\pm 5.4 \%$, $36.4 \pm 6.4 \%$, and $34.6 \pm 4.4 \%$ in group II; $36.9 \pm 2.0 \%, 35.9 \pm 2.3 \%$, and $36.7 \pm 2.4 \%$ in group III; $40.7 \pm 6.3 \%, 40.0 \pm 5.8 \%$, and $40.2 \pm 5.7 \%$ in group IV; $33.6 \pm 3.3 \%, 32.6 \pm 3.6 \%$, and $34.5 \pm$ $2.9 \%$ in group $\mathrm{V}$; and $33.4 \pm 6.6 \%, 34.2 \pm 5.8 \%$, and $35.4 \pm 6.2 \%$ in group VI. There were no significant differences among the six groups on the same day or among different days within the same group. In group I, thickening fraction on day 1 was virtually identical at baseline and after vehicle administration (preocclusion; Fig. 4). In group II, thickening fraction on day 1 was $32.4 \pm 5.4 \%$ at baseline and $31.9 \pm 5.6 \%$ after administration of $5 \mathrm{mg} / \mathrm{kg}$ of chelerythrine (preocclusion; $P=\mathrm{NS}$; Fig. 5), indicating that this agent had no significant effect on regional function in normal myocardium. Similar results were obtained in group III $(36.9 \pm 2.0 \%$ before and $37.4 \pm 2.2 \%$ after $0.5 \mathrm{mg} / \mathrm{kg}$ of chelerythrine) and in group V (33.6 $\pm 3.3 \%$ before and $31.6 \pm 5.8 \%$ after chelerythrine). In group VI, administration of PMA on day 1 had no significant effect on thickening fraction (33.4 $\pm 6.6 \%$ before and $33.4 \pm 5.2 \% 5$ min after PMA).

Figs. 4-9 demonstrate the serial measurements of thickening fraction during the six occlusion/reperfusion cycles and the 5-h recovery phase, expressed as a percentage of preocclusion measurements, in group I, II, III, IV, V, and VI, respectively. We shall first describe the control group and then the treated groups.

Group I (control). On day 1, thickening fraction recovered

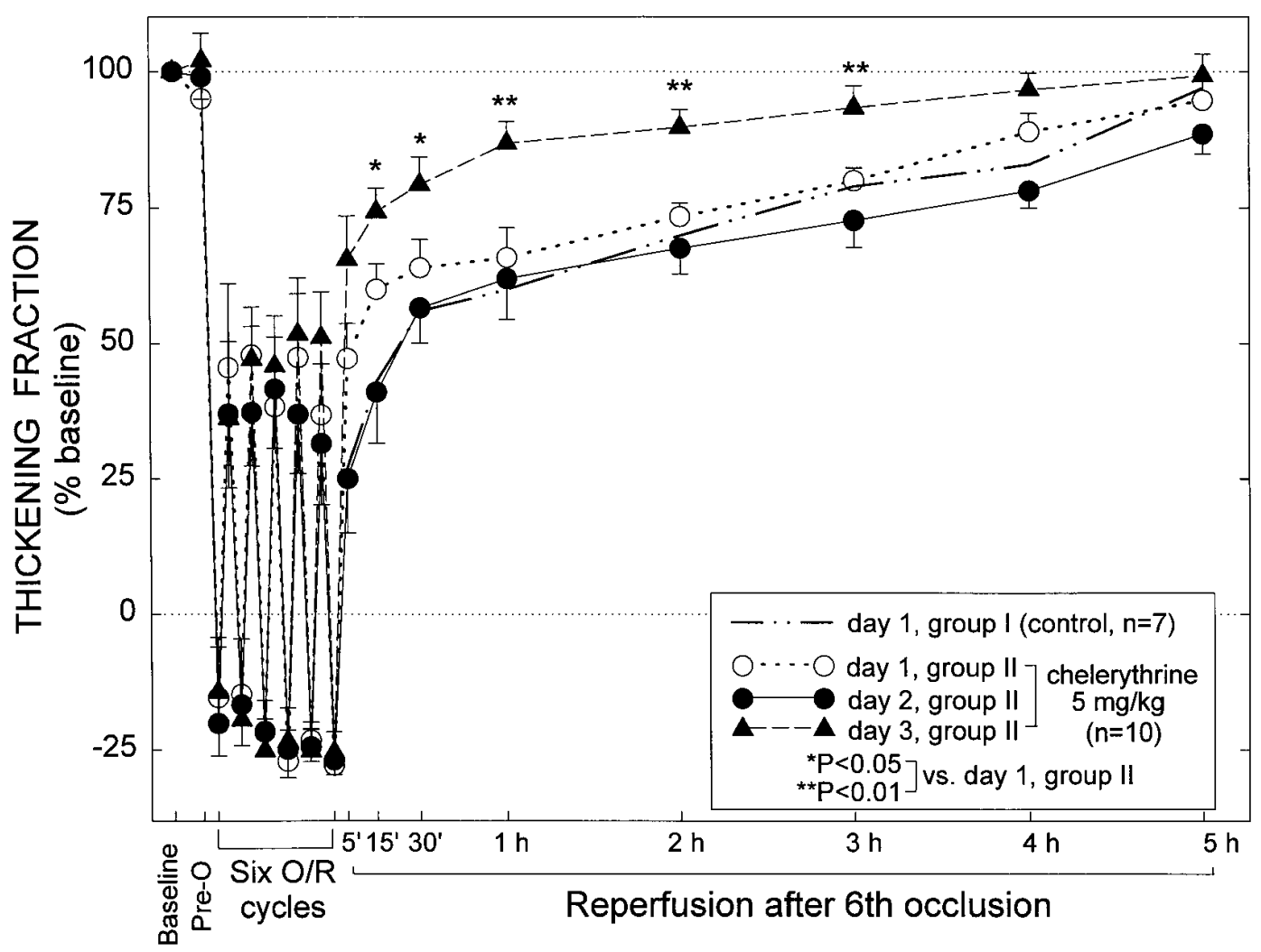

the data pertaining to day 1 of group I (control group) are also shown (thick interrupted line without symbols, $n=7$ ). Thickening fraction is expressed as a percentage of preocclusion values. Data are means \pm SEM.
Figure 5. Systolic thickening fraction in the ischemic-reperfused region in group II (chelerythrine $5 \mathrm{mg} / \mathrm{kg}$ ) before administration of chelerythrine (Baseline), $4 \mathrm{~min}$ after the bolus of chelerythrine (immediately before the first occlusion; preocclusion $[$ Pre-O]), 3 min into each coronary occlusion $(O)$, 3 min into each reperfusion $(R)$, and at selected times during the 5-h reperfusion interval after the sixth occlusion. Measurements taken on day 1 are represented by the dashed line with open circles, measurements taken on day 2 are represented by the continuous line with solid circles, and measurements taken on day 3 are represented by the interrupted line with solid triangles $(n=$ 10 for all three days). To facilitate comparisons, 


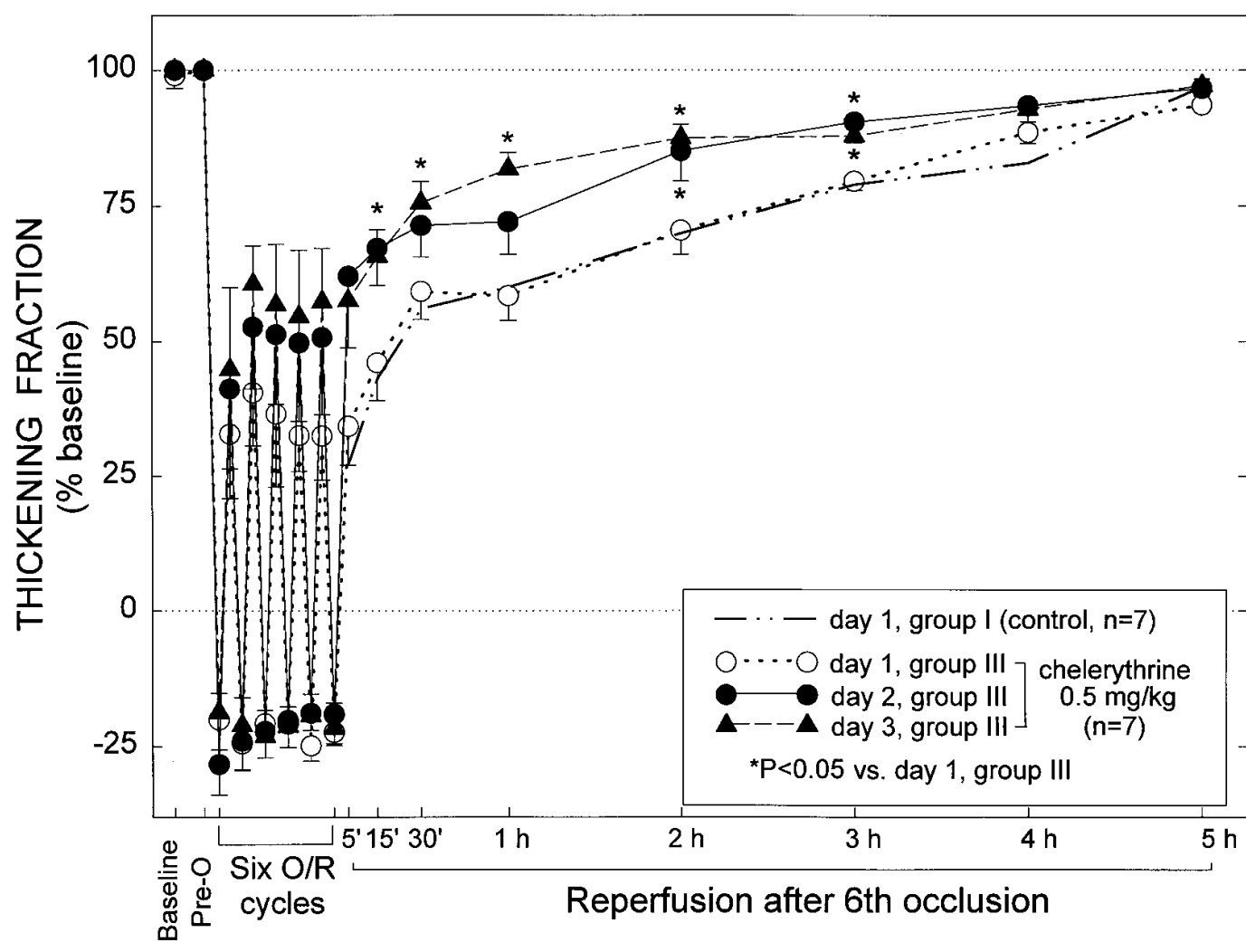

data pertaining to day 1 of group I (control group) are also shown (thick interrupted line without symbols, $n=7$ ). Thickening fraction is expressed as a percentage of preocclusion values. Data are means \pm SEM.
Figure 6. Systolic thickening fraction in the ischemic-reperfused region in group III (chelerythrine $0.5 \mathrm{mg} / \mathrm{kg}$ ) before administration of chelerythrine (Baseline), 4 min after the bolus of chelerythrine (immediately before the first occlusion; preocclusion [Pre-O]), 3 min into each coronary occlusion $(O)$, 3 min into each reperfusion $(R)$, and at selected times during the 5-h reperfusion interval following the sixth occlusion.

Measurements taken on day 1 are represented by the dashed line with open circles, measurements taken on day 2 are represented by the continuous line with solid circles, and measurements taken on day 3 are represented by the interrupted line with solid triangles $(n=7$ for all three days). To facilitate comparisons, the to only $37.3 \pm 9.9 \%$ of baseline after the first coronary occlusion/reperfusion cycle (Fig. 4). Little additional deterioration was noted with the subsequent five cycles, so that $5 \mathrm{~min}$ after the sixth reperfusion, thickening fraction averaged 32.0 \pm $11.0 \%$ of baseline values (Fig. 4). Contractile function remained significantly depressed for $4 \mathrm{~h}$ after the sixth reperfusion, with thickening fraction averaging $43.0 \pm 7.0 \%$ of baseline values at $30 \mathrm{~min}$ ( $P<0.01$ vs. baseline values $), 60.0 \pm 7.5 \%$ at $1 \mathrm{~h}$ $(P<0.01), 72.1 \pm 3.0 \%$ at $2 \mathrm{~h}(P<0.01), 78.9 \pm 7.0 \%$ at $3 \mathrm{~h}(P<$ $0.01)$, and $86.0 \pm 3.2 \%$ at $4 \mathrm{~h}(P<0.01$; Fig. 4$)$. Thus, the sequence of six 4-min occlusions resulted in severe myocardial stunning, which lasted, on average, $4 \mathrm{~h}$.

On day 2, the recovery of WTh after the six 4-min occlusions was markedly improved compared with day 1 (Fig. 4). Statistical analysis demonstrated that the measurements of thickening fraction were significantly greater than those on day 1 at $15 \min (P<0.05), 1 \mathrm{~h}(P<0.05), 2 \mathrm{~h}(P<0.01)$, and $4 \mathrm{~h}(P<0.05)$ of reperfusion. Whereas it took $5 \mathrm{~h}$ for thickening fraction to return to $\sim 90 \%$ of baseline values on day 1 , on day 2 , thickening fraction reached $92 \%$ of baseline after just $3 \mathrm{~h}$ of reperfusion. The total deficit of WTh after the sixth reperfusion was $49 \%$ less on day 2 compared with day $1(P<0.05$; Fig. $10)$. On day 3 , the recovery of WTh after the six 4-min occlusions was again enhanced compared with day 1 and similar to that observed on day 2 (Fig. 4). The total deficit of WTh after the sixth reperfusion was $48 \%$ less on day 3 compared with day $1(P<0.05$; Fig. 10). Thus, myocardial stunning was attenuated markedly, and to a similar extent, on days 2 and 3 compared with day 1.
Group II (chelerythrine $5 \mathrm{mg} / \mathrm{kg}$ ). On day 1 , both the recovery of WTh (Fig. 5) and the total deficit of WTh (Fig. 10) were similar to those observed in the control group, indicating that chelerythrine had no appreciable effect on the severity of myocardial stunning on day 1 . On day 2 , however, the results were quite different from those obtained in the control group. Unlike the pattern observed in controls, in chelerythrinetreated rabbits the recovery of WTh during the 5-h final reperfusion period was not improved compared with day 1 (Fig. 5), so that the total deficit of WTh on day 2 was not less than that observed on day 1 (Fig. 10). The total deficit of WTh on day 2 was $119 \%$ greater than the corresponding value in control rabbits $(P<0.05)$ and was similar to that observed in control rabbits on day 1 (Fig. 10). Thus, the administration of $5 \mathrm{mg} / \mathrm{kg}$ of chelerythrine on day 1 completely prevented the development of PC on day 2. On day 3, however, the recovery of WTh in chelerythrine-treated rabbits was markedly improved compared with day 2 (Fig. 5) and was similar to that noted on day 2 in the control group (Fig. 4). The total deficit of WTh was $56 \%$ less than that noted on day 2 in the same animals $(P<0.05)$ and was comparable to that noted on day 2 in control rabbits (Fig. 10). Thus, in rabbits treated with $5 \mathrm{mg} / \mathrm{kg}$ of chelerythrine the sequence of six coronary occlusions and reperfusions performed on day 1 failed to precondition against stunning on day 2 , but the same sequence performed on day 2 did precondition against stunning on day 3 .

Group III (chelerythrine $0.5 \mathrm{mg} / \mathrm{kg}$ ). On day 1 , both the recovery of WTh (Fig. 6) and the total deficit of WTh (Fig. 10) were similar to those observed in the control group. In contrast 


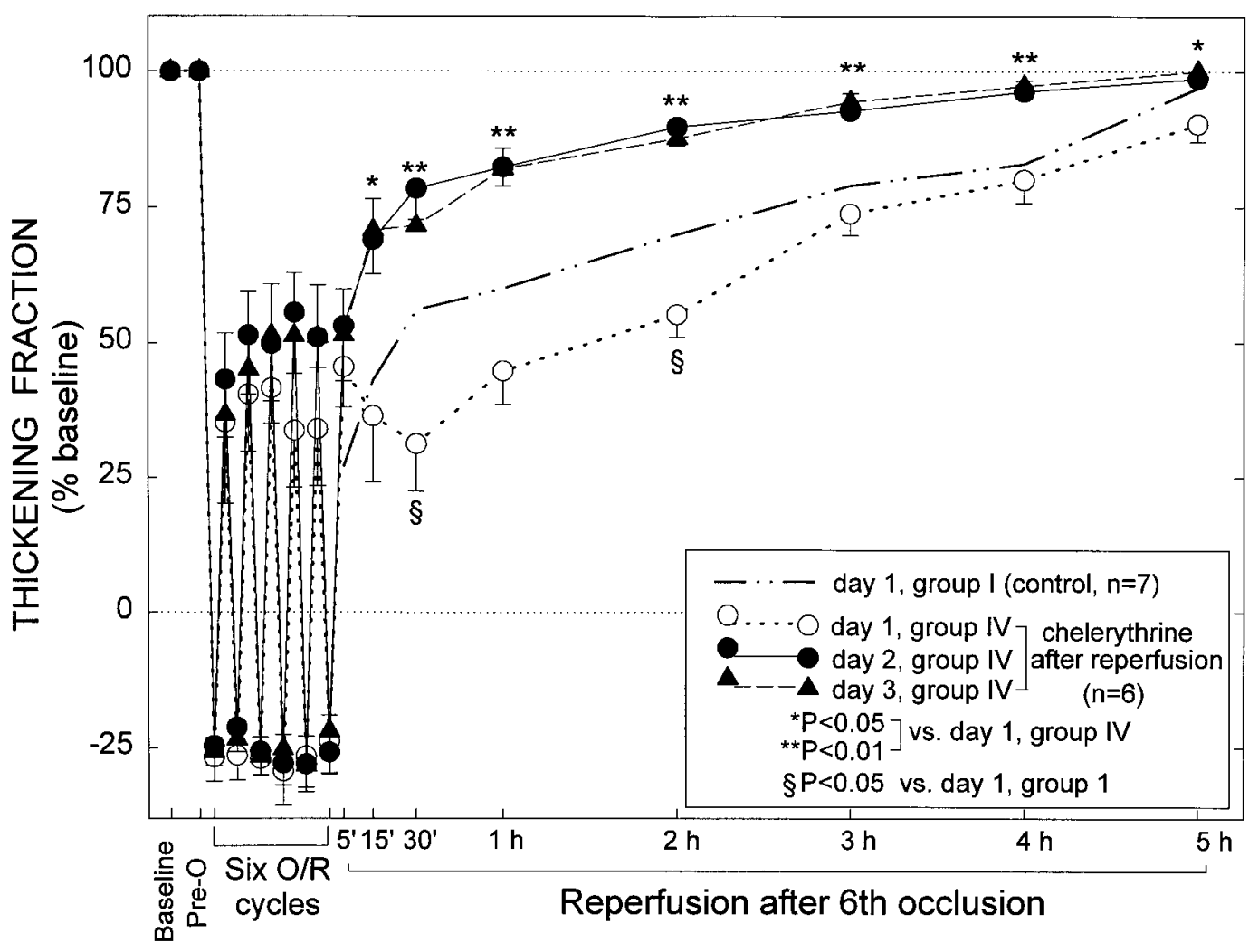

Figure 7. Systolic thickening fraction in the ischemic-reperfused region in group IV (chelerythrine $5 \mathrm{mg} / \mathrm{kg}$ after reperfusion) at baseline, 4 min later (immediately before the first occlusion; preocclusion [Pre-O]), 3 min into each coronary occlusion $(O)$, 3 min into each reperfusion $(R)$, and at selected times during the 5-h reperfusion interval after the sixth occlusion. Measurements taken on day 1 are represented by the dashed line with open circles, measurements taken on day 2 are represented by the continuous line with solid circles, and measurements taken on day 3 are represented by the interrupted line with solid triangles $(n=6$ for all three days). To facilitate comparisons, the data pertaining to day 1 of group I (control group) are also shown (thick interrupted line without symbols, $n=7$ ). Thickening fraction is expressed as a percentage of preocclusion values. Data are means \pm SEM.

to group II, in group III a late PC effect became apparent on day 2 . The recovery of WTh on day 2 was significantly faster than on day 1 (Fig. 6) and was essentially indistinguishable from that observed on day 2 in control rabbits (Fig. 4). As a result, the total deficit of WTh after the sixth reperfusion was $40 \%$ less on day 2 compared with day 1 ( $P<0.05$; Fig. 10$)$. The recovery of WTh did not improve appreciably on day 3 as compared with day 2 (Figs. 6 and 10), indicating that a full PC effect had been achieved on day 2 . Thus, in contrast to the results obtained in group II with a 10-fold higher dose of chelerythrine $(5 \mathrm{mg} / \mathrm{kg})$, in group III a dose of $0.5 \mathrm{mg} / \mathrm{kg}$ of chelerythrine failed to block the development of late PC against stunning.

Group IV (chelerythrine after reperfusion). This group was studied to determine whether administration of a PKC inhibitor after the translocation of PKC $\epsilon$ and $\eta$ has occurred can still block late PC. On day 1, rabbits underwent the six cycles of coronary occlusion/reperfusion and were given $5 \mathrm{mg} / \mathrm{kg}$ of chelerythrine 10 min after the sixth reperfusion (Fig. 1). Administration of chelerythrine produced a transient deterioration of WTh, which persisted up to $2 \mathrm{~h}$ after reperfusion (Fig. 7). As a result, the total deficit of WTh on day 1 was $58 \%$ greater than that observed in controls $(P<0.05$; Fig. 10). On days 2 and 3, however, both the recovery of WTh (Fig. 7) and the total deficit of WTh (Fig. 10) were similar to those observed in the control group. Thus, in contrast to the results obtained when $5 \mathrm{mg} / \mathrm{kg}$ of chelerythrine was given $5 \mathrm{~min}$ before the sequence of six occlusion/reperfusion cycles (group II), the same dose of chelerythrine given 10 min after the six occlusion/ reperfusion cycles failed to block the development of late PC against stunning.

Group V (chelerythrine pretreatment). This group was studied to rule out the possibility that the prevention of late PC against stunning observed on day 2 in group II may have been caused by a delayed adverse effect on myocardial contractility occurring as a result of chelerythrine administration on day 1 . On day 1, rabbits received chelerythrine as in group II but did not undergo coronary occlusion, and then underwent the coronary occlusion/reperfusion protocols on days 2 and 3 (Fig. 1). On day 2, the recovery of WTh during the $5 \mathrm{~h}$ of reperfusion was similar to that observed on day 1 in the control group (Fig. 8 ), so that the total deficit of WTh after the sixth reperfusion did not differ significantly from that observed in control rabbits on day 1 (Fig. 10). On day 3 , the recovery of WTh was significantly faster than on day 2 (Fig. 8), and the total deficit of WTh was comparable to that observed on day 2 in control rabbits (Fig. 10). Thus, administration of chelerythrine did not exacerbate the severity of myocardial stunning $24 \mathrm{~h}$ later. These results indicate that the absence of late PC against stunning on day 2 in group II cannot be ascribed to a delayed deleterious action of chelerythrine.

Group VI (PMA pretreatment). In this group, rabbits received PMA in the absence of ischemia on day 1 and then were subjected to the coronary occlusion/reperfusion sequence on days 2 and 3. On day 2, the recovery of WTh during the $5 \mathrm{~h}$ of reperfusion was significantly improved compared with that ob- 


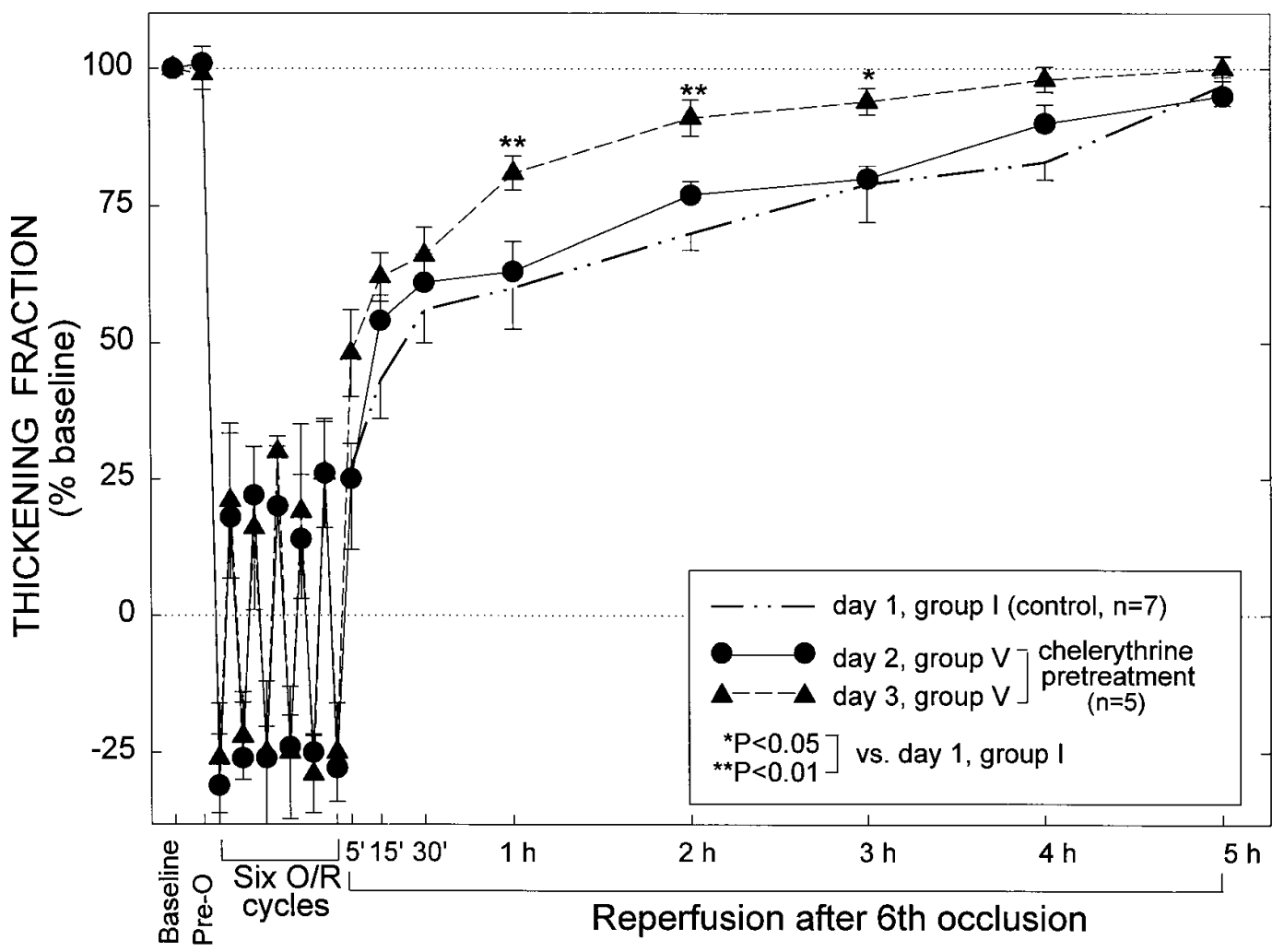
facilitate comparisons,
the data pertaining to day 1 of group I (control group) are also shown (thick interrupted line without symbols, $n=7$ ). Thickening fraction is ex-

pressed as a percentage of preocclusion values. Data are means \pm SEM.
Figure 8. Systolic thickening fraction in the ischemic-reperfused region in group $\mathrm{V}$ (chelerythrine pretreatment) at baseline, 4 min later (immediately before the first occlusion; preocclusion $[$ Pre-O]), 3 min into each coronary occlusion $(O), 3$ min into each reperfusion $(R)$, and at selected times during the 5-h reperfusion interval after the sixth occlusion. Because these rabbits did not undergo coronary occlusion on day 1 , only measurements obtained on days 2 and 3 of the protocol are shown. Measurements taken on day 2 are represented by the continuous line with solid circles, whereas measurements taken on day 3 are represented by the interrupted line with solid triangles ( $n=5$ for both days). To .

served on day 1 in the control group (Fig. 9), so that the total deficit of WTh after the sixth reperfusion was $40 \%$ less than that observed in control rabbits on day $1(P<0.05)$ and not significantly different from that observed in control rabbits on day 2 (Fig. 10). Thus, administration of PMA in lieu of ischemia significantly attenuated myocardial stunning $24 \mathrm{~h}$ later, and the magnitude of this effect was nearly equivalent to that observed after ischemic PC. On day 3, both the recovery of WTh (Fig. 9) and the total deficit of WTh (Fig. 10) were similar to those observed on day 2 , indicating that the ischemia induced on day 2 caused little additional PC compared to treatment with PMA on day 1.

\section{Phase B: Studies of PKC activity and subcellular distribution}

Exclusions. Of the 27 rabbits instrumented for phase B, five were assigned to group VII (control group), five to group VIII (PC without chelerythrine), five to group IX (chelerythrine 5 $\mathrm{mg} / \mathrm{kg}$ without PC), seven to group X (PC with chelerythrine 5 $\mathrm{mg} / \mathrm{kg}$ ), and five to group XI (PC with chelerythrine $0.5 \mathrm{mg}$ / $\mathrm{kg}$ ). Of the seven rabbits assigned to group $\mathrm{X}$, two succumbed to ventricular fibrillation (one during the first occlusion and one during the second occlusion). All rabbits in groups VII, VIII, IX, and XI successfully completed the protocol.

Effect of ischemic PC on PKC activity. As elaborated in the Discussion, the measurements of PKC activity obtained with our assay system in the presence of calcium represent the total activity of all of the $10 \mathrm{PKC}$ isoforms expressed in the rabbit heart (8), whereas the measurements obtained in the absence of calcium reflect mainly the activity of the subgroups of novel PKC isoforms $(\delta, \epsilon, \zeta$, and $\eta)$ and atypical PKC isoforms $(\iota, \lambda$, and $\mu)$, which are calcium-independent (45). As illustrated in Fig. 11, the sequence of six cycles of 4-min occlusion/4-min reperfusion had no appreciable effect on total PKC activity, either in the presence or in the absence of calcium: calcium-stimulated $\mathrm{PKC}$ activity was $179 \pm 8 \mathrm{pmol} / \mathrm{min} / \mathrm{mg}$ protein in group VII (control) versus $186 \pm 9 \mathrm{pmol} / \mathrm{min} / \mathrm{mg}$ protein in group VIII (ischemic PC); calcium-independent PKC activity averaged $132 \pm 7 \mathrm{pmol} / \mathrm{min} / \mathrm{mg}$ protein in group VII versus $130 \pm 6 \mathrm{pmol} / \mathrm{min} / \mathrm{mg}$ protein in group VIII $(P=\mathrm{NS})$. Furthermore, the sequence of six occlusion/reperfusion cycles had no significant effect on the subcellular distribution of PKC activity: the cytosolic fraction of calcium-stimulated PKC activity was $88 \pm 4 \%$ in group VII and $89 \pm 3 \%$ in group VIII, whereas the cytosolic fraction of calcium-independent PKC activity was $91 \pm 3 \%$ in group VII and $85 \pm 5 \%$ in group VIII $(P=\mathrm{NS})$. Thus, PKC activity resided mostly in the cytosol in all groups. These results are in keeping with our previous findings (8) and indicate that ischemic PC is not associated with demonstrable changes either in total PKC activity or in the subcellular distribution of PKC activity.

Effect of chelerythrine on PKC activity. In the absence of coronary occlusions, the higher dose of chelerythrine $(5 \mathrm{mg} / \mathrm{kg})$ effected a $45 \%$ reduction in total myocardial calcium-stimulated PKC activity $(99 \pm 5 \mathrm{pmol} / \mathrm{min} / \mathrm{mg}$ protein in group IX [chelerythrine without $\mathrm{PC}$ ] versus $179 \pm 8 \mathrm{pmol} / \mathrm{min} / \mathrm{mg}$ protein in group VII [control]; $P<0.05$; Fig. 11). Chelerythrine at 5 


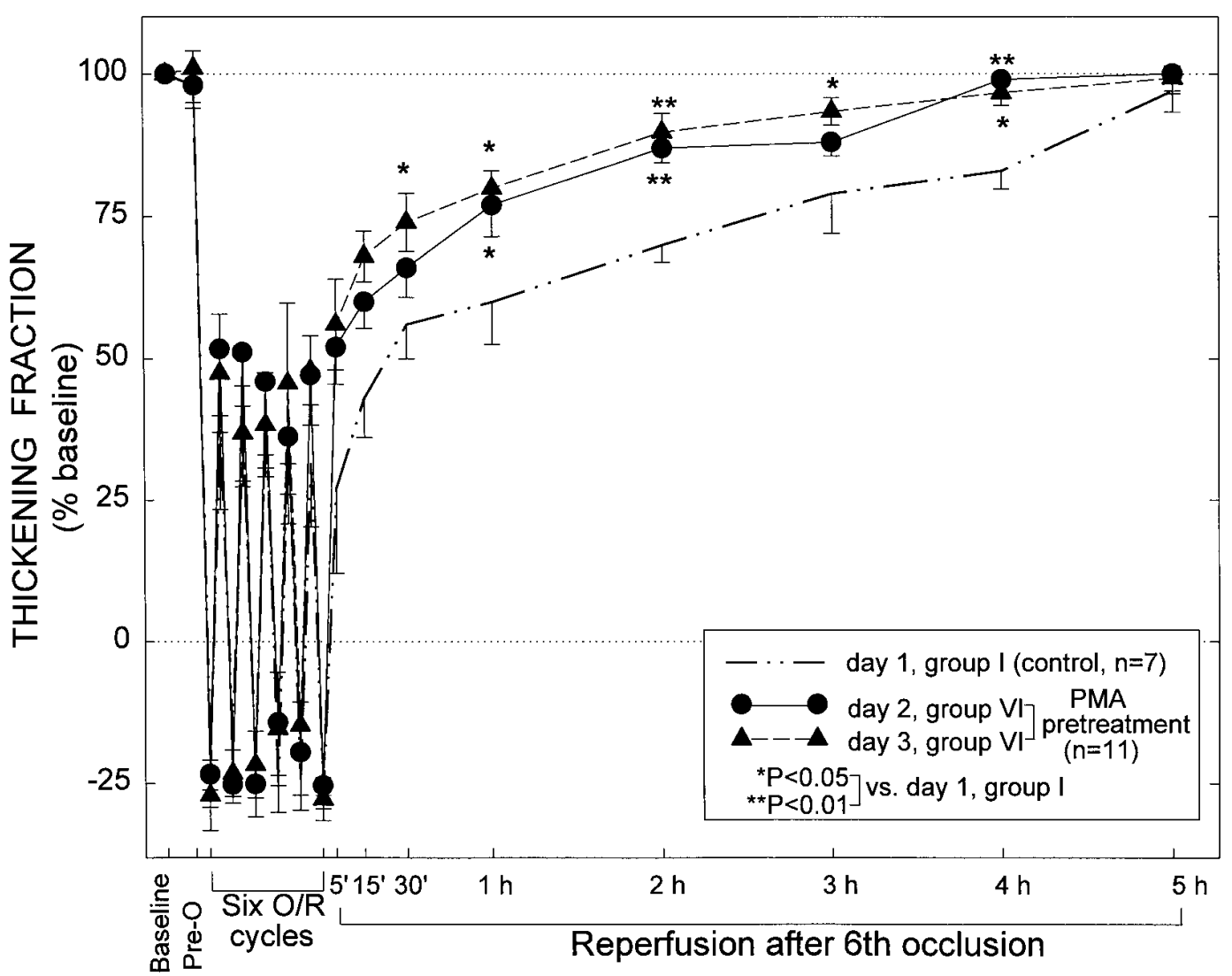

Figure 9. Systolic thickening fraction in the ischemic-reperfused region in group VI ( $P M A$ pretreatment) at baseline, 4 min later (immediately before the first occlusion; preocclusion [Pre-O]),

3 min into each coronary occlusion $(O), 3$ min into each reperfusion $(R)$, and at selected times during the 5-h reperfusion interval after the sixth occlusion. Because these rabbits did not undergo coronary occlusion on day 1 , only measurements obtained on days 2 and 3 of the protocol are shown. Measurements taken on day 2 are represented by the continuous line with solid circles, whereas measurements taken on day 3 are represented by the interrupted line with solid triangles $(n=11$ for both days). To facilitate comparisons, the data pertaining to day 1 of group I (control group) are also shown (thick interrupted line without symbols, $n=7$ ). Thickening fraction is expressed as a percentage of preocclusion values. Data are means \pm SEM. $\mathrm{mg} / \mathrm{kg}$ also effected a $37 \%$ reduction in calcium-independent $\mathrm{PKC}$ activity, from $132 \pm 7 \mathrm{pmol} / \mathrm{min} / \mathrm{mg}$ protein in group VII to $83 \pm 5 \mathrm{pmol} / \mathrm{min} / \mathrm{mg}$ protein in group IX $(P<0.05$; Fig. 11$)$. A similar effect was observed in the rabbits that underwent six cycles of coronary occlusion/reperfusion. In these animals, 5 $\mathrm{mg} / \mathrm{kg}$ of chelerythrine decreased total myocardial calciumstimulated PKC activity by $47 \%$ (from $186 \pm 9 \mathrm{pmol} / \mathrm{min} / \mathrm{mg}$ protein in group VIII [PC without chelerythrine] to $98 \pm 7$ $\mathrm{pmol} / \mathrm{min} / \mathrm{mg}$ protein in group $\mathrm{X}$ [PC with chelerythrine 5 $\mathrm{mg} / \mathrm{kg}], P<0.05$; Fig. 11); calcium-independent activity was reduced by $32 \%$, from $130 \pm 6 \mathrm{pmol} / \mathrm{min} / \mathrm{mg}$ protein in group VIII to $89 \pm 7 \mathrm{pmol} / \mathrm{min} / \mathrm{mg}$ protein in group $\mathrm{X}(P<0.05$; Fig. 11). These results indicate that the administration of $5 \mathrm{mg} / \mathrm{kg}$ of chelerythrine attenuated both calcium-stimulated and calcium-independent PKC activity, and that the magnitude of these effects was comparable in the absence and presence of ischemic PC. In contrast, the lower dose of chelerythrine $(0.5$ $\mathrm{mg} / \mathrm{kg}$ ) had no effect on either calcium-stimulated or calciumindependent PKC activity (182 \pm 4 and $127 \pm 6 \mathrm{pmol} / \mathrm{min} / \mathrm{mg}$ protein, respectively, in group XI; Fig. 11). Neither dose of chelerythrine had any appreciable effect on the subcellular distribution of total PKC activity. The cytosolic fraction of calcium-stimulated PKC activity (expressed as a percentage of to- tal activity) was $88 \pm 4 \%$ in group VII, $89 \pm 3 \%$ in group VIII, $87 \pm 1 \%$ in group IX, $86 \pm 1 \%$ in group $X$, and $90 \pm 3 \%$ in group XI $(P=$ NS), whereas the cytosolic fraction of calcium-independent PKC activity was $91 \pm 3 \%$ of total in group VII, $85 \pm 5 \%$ in group VIII, $94 \pm 2 \%$ in group IX, $86 \pm 6 \%$ in group $\mathrm{X}$, and $88 \pm 4 \%$ in group XI $(P=\mathrm{NS})$.

Effect of ischemic PC on the subcellular distribution of PKC $\epsilon$ and $\eta$. The sequence of six cycles of 4-min coronary occlusion/4-min reperfusion caused significant translocation of both the $\epsilon$ and $\eta$ isoforms of PKC: the particulate fraction of PKC $\epsilon$ increased from $38 \pm 3 \%$ of total $\epsilon$ protein in group VII (control group) to $63 \pm 4 \%$ in group VIII (PC group; $P<0.05$; Fig. 12 ), whereas the particulate fraction of $\mathrm{PKC} \eta$ rose from $67 \pm 3 \%$ of total $\eta$ protein in group VII to $86 \pm 3 \%$ in group VIII $(P<$ 0.05; Fig. 12). Because, under control conditions, the proportion of PKC isoform $\eta$ associated with the particulate fraction was greater than the corresponding value for PKC $\epsilon(67 \%$ versus $38 \%$ of total protein, respectively, in group VII), the percent increases in the particulate fraction induced by PC in group VIII were larger for $\epsilon$ than for $\eta$ ( $66 \%$ versus $28 \%$, respectively). Thus, in keeping with our previous results (8), the present data indicate that ischemic $\mathrm{PC}$ caused translocation of both the $\epsilon$ and $\eta$ isoforms of PKC, and that the magnitude of 


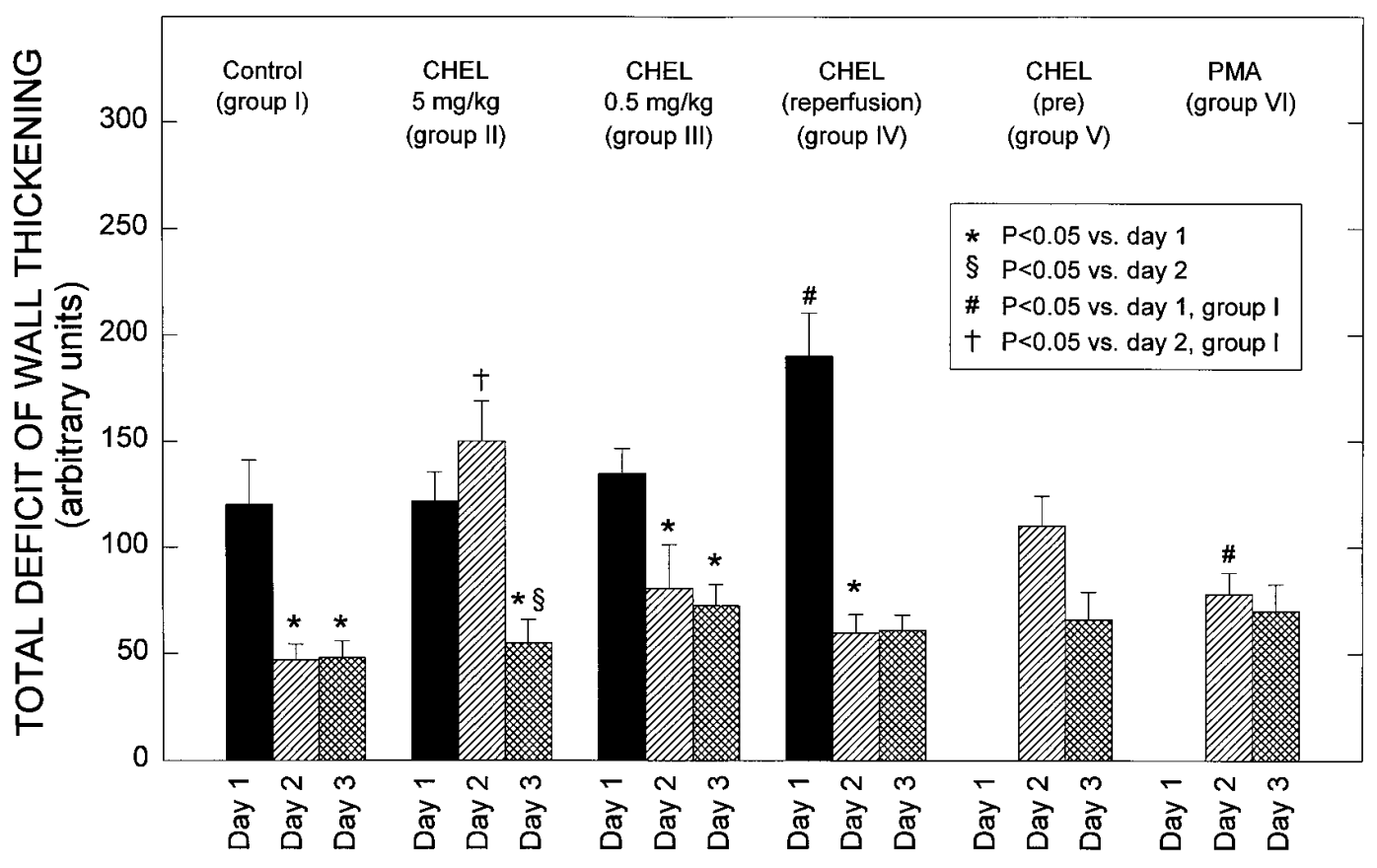

Figure 10. Total deficit of WTh after the sixth reperfusion on days 1,2 , and 3 in the control $(n=7)$, chelerythrine (CHEL) $5 \mathrm{mg} / \mathrm{kg}(n=10)$, chelerythrine $0.5 \mathrm{mg} / \mathrm{kg}(n=$ 7), chelerythrine after reperfusion $(n=6)$, chelerythrine pretreatment $(n=5)$, and PMA pretreatment $(n=11)$ groups (groups I, II, III, IV, V, and VI, respectively). The total deficit of WTh was measured in arbitrary units (see text). Data are means \pm SEM. this phenomenon was greater for the former than for the latter. Ischemic PC caused no significant translocation of other $\mathrm{PKC}$ isoforms (data not shown).

Effect of chelerythrine on the subcellular distribution of $P K C \epsilon$ and $\eta$. Western immunoblots illustrating the effect of chelerythrine on PKC $\epsilon$ translocation are presented in Fig. 3. In groups VII (control) and IX (chelerythrine $5 \mathrm{mg} / \mathrm{kg}$ without $\mathrm{PC})$, most of the PKC $\epsilon$ protein was found in the cytosolic fraction (Fig. 3, top); in groups X (PC with chelerythrine $5 \mathrm{mg} / \mathrm{kg}$ ) and XI (PC with chelerythrine $0.5 \mathrm{mg} / \mathrm{kg}$ ), the pattern was similar, that is, most of the $\epsilon$ protein was still present in the cytosolic fraction (Fig. 3, bottom). Therefore, after administration of either 5 or $0.5 \mathrm{mg} / \mathrm{kg}$ of chelerythrine, the six coronary occlu- sion/reperfusion cycles failed to change the subcellular distribution of PKC $\epsilon$.

Fig. 12 shows that the particulate fractions of $\epsilon$ and $\eta$ were not appreciably different in group IX (chelerythrine $5 \mathrm{mg} / \mathrm{kg}$ without PC) versus group X (PC with chelerythrine $5 \mathrm{mg} / \mathrm{kg}$ ). Thus, the higher dose of chelerythrine $(5 \mathrm{mg} / \mathrm{kg})$ completely prevented the translocation of both PKC $\epsilon$ and $\eta$ induced by ischemic PC. This dose of chelerythrine had no effect on the subcellular distribution of the other PKC isoforms (data not shown). In group XI (PC with chelerythrine $0.5 \mathrm{mg} / \mathrm{kg}$ ), the particulate fraction of $\mathrm{PKC} \eta$ was virtually indistinguishable from that measured in group VII (control group) (67 $\pm 2 \%$ versus $67 \pm 3 \%$ of total, respectively; Fig. 12). In contrast, in group

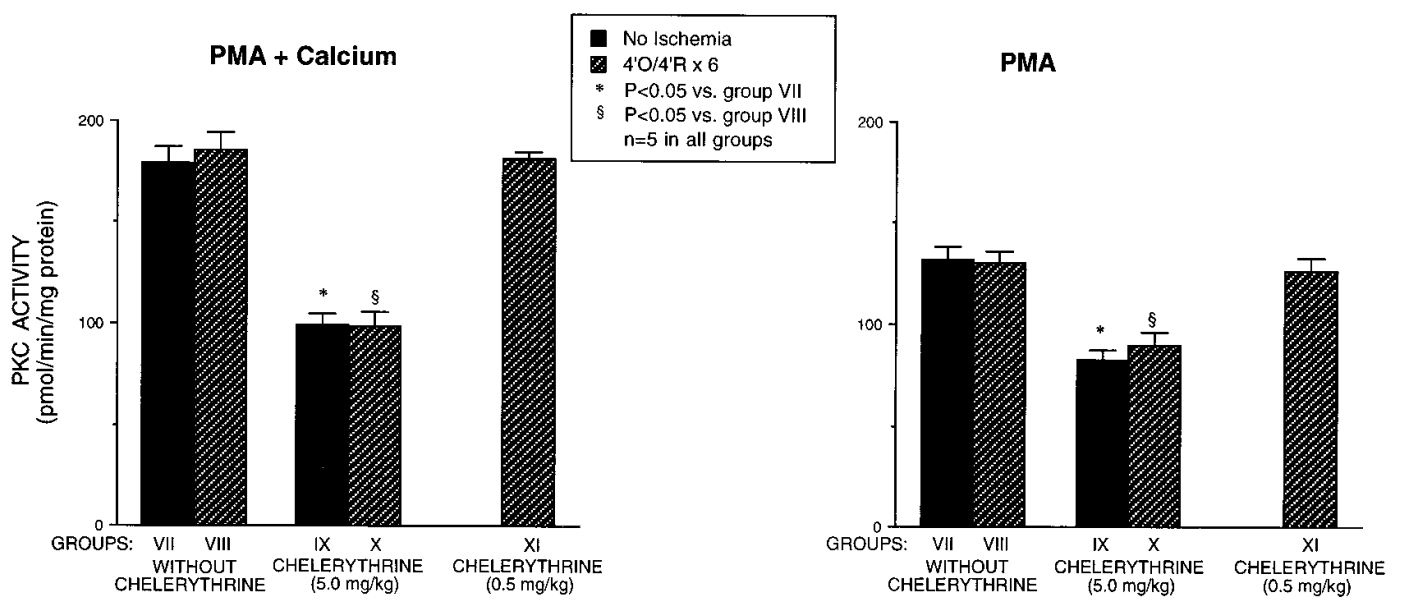

Figure 11. Effect of chelerythrine on total PKC activity. PMA-stimulated PKC activity was measured in the presence or absence of calcium (calcium-stimulated and calcium-independent PKC activity, respectively; see Methods). (Left) Calcium-stimulated total PKC activity in groups VII (controls, $n=5$ ), VIII (PC without chelerythrine, $n=5$ ), IX (chelerythrine $5 \mathrm{mg} / \mathrm{kg}$ without PC, $n=5$ ), X (PC with chelerythrine

$5 \mathrm{mg} / \mathrm{kg}, n=5$ ), and XI (PC with chelerythrine $0.5 \mathrm{mg} / \mathrm{kg}, n=5$ ). (Right) Calcium-independent total PKC activity in groups VII, VIII, IX, X, and XI. Six cycles of 4-min coronary occlusion/reperfusion $\left(4^{\prime} O / 4^{\prime} R\right)$ did not produce any demonstrable change in either calcium-stimulated or calcium-independent total PKC activity. Chelerythrine at the higher dose $(5 \mathrm{mg} / \mathrm{kg})$ significantly attenuated both activities, and this effect was similar in the absence or presence of six cycles of 4-min occlusion/reperfusion. Chelerythrine at the lower dose $(0.5 \mathrm{mg} / \mathrm{kg}) \mathrm{had} \mathrm{no}$ effect on either calcium-stimulated or calcium-independent total PKC activity. Data are means \pm SEM. 

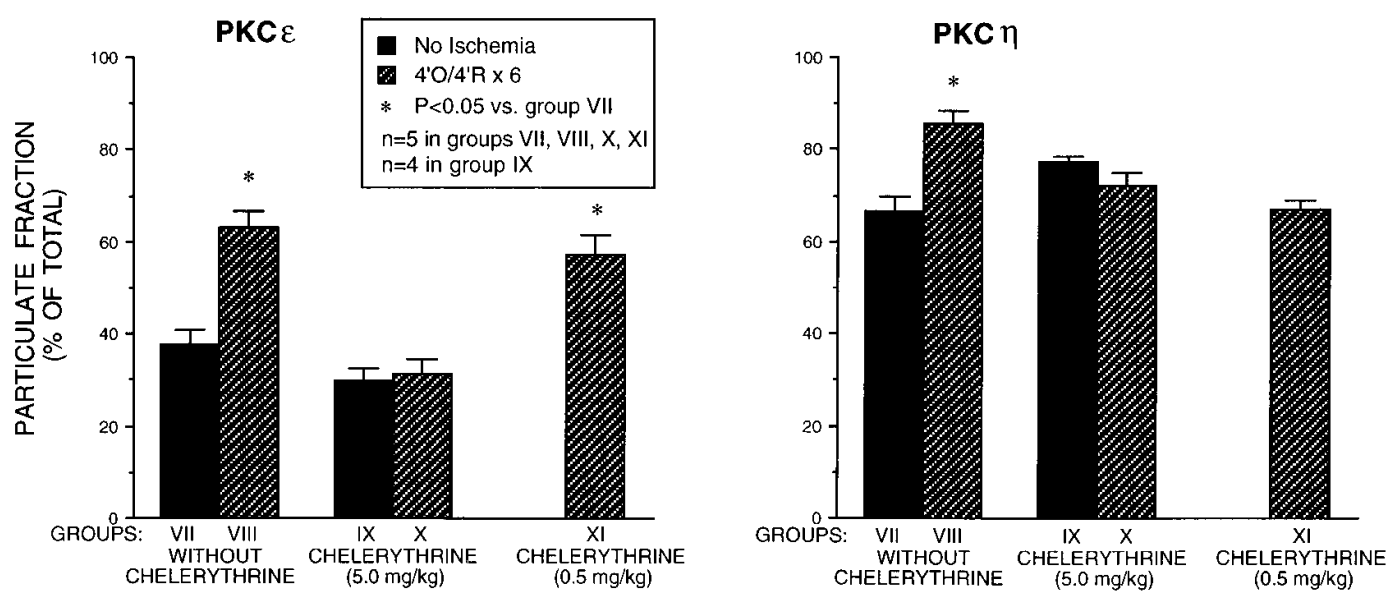

Figure 12. Effect of chelerythrine on the translocation of PKC isoforms $\epsilon$ and $\eta$ induced by ischemic PC. (Left) Subcellular distribution of PKC $\epsilon$ in groups VII (controls, $n=5$ ), VIII (PC without chelerythrine, $n=5$ ), IX (chelerythrine $5 \mathrm{mg} / \mathrm{kg}$ without PC, $n=4), \mathrm{X}$ (PC with chelerythrine $5 \mathrm{mg} / \mathrm{kg}, n=5$ ), and XI (PC with chelerythrine $0.5 \mathrm{mg} / \mathrm{kg}, n=5$ ). (One of the five rabbits in group IX was not examined by Western immunoblotting due to technical problems.) When compared with group VII, the particulate fraction of $\epsilon$ protein was significantly $(P<0.05)$ increased in group VIII, indicating that the PC protocol used in this study (six cycles of 4-min coronary occlusion/4-min reperfusion $\left[4^{\prime} O / 4^{\prime} R\right]$ ) induced translocation of PKC $\epsilon$. At a dose of $5 \mathrm{mg} / \mathrm{kg}$, chelerythrine completely prevented the translocation of PKC $\epsilon$ induced by ischemic PC (group X). In contrast, $0.5 \mathrm{mg} / \mathrm{kg}$ of chelerythrine had no significant effect on PKC $\epsilon$ translocation (group XI). (Right) Subcellular distribution of PKC $\eta$ in groups VII (controls, $n=5$ ), VIII (PC without chelerythrine, $n=5$ ), IX (chelerythrine $5 \mathrm{mg} / \mathrm{kg}$ without PC, $n=4), \mathrm{X}(\mathrm{PC}$ with chelerythrine $5 \mathrm{mg} / \mathrm{kg}$, $n=5$ ), and XI (PC with chelerythrine $0.5 \mathrm{mg} / \mathrm{kg}, n=5$ ). (One of the five rabbits in group IX was not examined by Western immunoblotting due to technical problems.) When compared with group VII, the particulate fraction of $\eta$ protein was significantly $(P<0.05)$ increased in group VIII, indicating that the PC protocol used in this study induced translocation of PKC $\eta$. Chelerythrine completely prevented the translocation of PKC $\eta$ induced by ischemic PC, both at a dose of $5 \mathrm{mg} / \mathrm{kg}$ (group X) and at a dose of $0.5 \mathrm{mg} / \mathrm{kg}$ (group XI). Because in the control group (group VII) the particulate fraction of $\eta$ was greater than that of $\epsilon$, the percent increase induced by ischemic PC for $\eta$ was relatively less than that induced for $\epsilon$. Data are means \pm SEM.

$\mathrm{XI}$ the particulate fraction of $\mathrm{PKC} \epsilon$ was significantly increased compared with group VII (control group; $57 \pm 4 \%$ of total $\epsilon$ protein versus $38 \pm 3 \%$, respectively, $P<0.05)$, and was not significantly different from group VIII (PC without chelerythrine; $63 \pm 4 \%$ of total; Fig. 12). Thus, the lower dose of chelerythrine $(0.5 \mathrm{mg} / \mathrm{kg})$ had different effects on PKC $\epsilon$ and $\eta$ : it completely blocked the translocation of PKC $\eta$ induced by ischemic PC but it failed to prevent the translocation of PKC $\epsilon$. As elaborated in the Discussion, the demonstration that chelerythrine can have isoform-selective effects has implications for studies aimed at blocking ischemic PC with PKC antagonists in vivo.

\section{Discussion}

Salient findings. Numerous previous studies have examined the effect of PKC inhibitors on the early and late phases of ischemic PC, but none has documented that the doses of inhibitors used had an effect either on PKC activity or on the subcellular distribution of PKC isoforms in the animal models used. Furthermore, no previous investigation has examined the effects of PKC inhibitors in conscious animals. The salient findings of the present study can be summarized as follows: $(a)$ in conscious rabbits, administration of $5 \mathrm{mg} / \mathrm{kg}$ of chelerythrine before the PC ischemia on day 1 completely abolishes late PC against myocardial stunning on day 2 , whereas a 10 -fold lower dose $(0.5 \mathrm{mg} / \mathrm{kg})$ has no effect; $(b)$ the $5 \mathrm{mg} / \mathrm{kg}$ dose of chelerythrine has no effect when given after the $\mathrm{PC}$ ischemia on day $1 ;(c)$ exposure to PMA in lieu of ischemia on day 1 induces a protective effect equivalent to that of late PC against stunning on day $2 ;(d)$ the coronary occlusion/reperfusion protocol that induces late PC against stunning also induces selec- tive translocation of the $\epsilon$ and $\eta$ isoforms of PKC to the particulate fraction with no appreciable changes in total myocardial PKC activity or in its subcellular distribution; $(e)$ the dose of chelerythrine that blocks late PC against stunning $(5 \mathrm{mg} / \mathrm{kg})$ also blocks the translocation of PKC $\epsilon$, whereas the dose that fails to block late PC against stunning $(0.5 \mathrm{mg} / \mathrm{kg})$ also fails to block the translocation of PKC $\epsilon$; and $(f)$ in contrast, both doses of chelerythrine block the translocation of PKC $\eta$ (i.e., the translocation of $\eta$ does not correlate with late PC). Taken together, these results demonstrate that the mechanism of late PC against myocardial stunning in conscious rabbits involves a PKC-mediated signaling pathway, and specifically implicate one isoform of PKC (the $\epsilon$ isoform) in this phenomenon.

Previous studies have identified a role of PKC in early (1821, 23-25, 27-31, 33) and late (5) PC against myocardial infarction. To our knowledge, this is the first study to demonstrate that PKC plays an obligatory role in the development of late $\mathrm{PC}$ against myocardial stunning. This is also the first study (a) to demonstrate that inhibition of PKC translocation in vivo results in loss of protection; $(b)$ to identify one specific PKC isozyme (among the $10 \mathrm{PKC}$ isoforms expressed in the rabbit heart [8]) as the likely signaling mediator of PC in vivo; $(c)$ to demonstrate that $\mathrm{PKC}$ inhibitors can have isoform-selective effects in in vivo models of ischemic PC; and $(d)$ to examine the effect of PKC inhibition on ischemic PC (early or late) in conscious animals. The data collectively provide strong evidence to support the proposal that $\mathrm{PKC} \epsilon$ is a key component of the signal transduction pathways responsible for late $\mathrm{PC}$ against stunning.

Dose-dependent effects of chelerythrine on PKC in vivo. Chelerythrine was selected for this study because it is reported to be more selective for PKC than other widely used inhibi- 
tors, such as staurosporine and polymixin B (18), and because it has been reported to block the early (18) and the late (5) phases of PC against infarction. Chelerythrine is a tetracyclic aromatic compound and a naturally occurring alkaloid of the benzophenanthridine class. It is a very potent inhibitor of PKC $\left(\mathrm{IC}_{50} \sim 0.7 \mu \mathrm{M}\right)$ and reportedly has very high selectivity for PKC compared to protein kinase A (250:1), calcium/calmodulin-dependent protein kinase $(150: 1)$, or tyrosine protein kinase (150:1) (46).

Our higher dose of chelerythrine $(5 \mathrm{mg} / \mathrm{kg})$ was selected on the basis of preliminary experiments which showed that this dosage was sufficient to block PMA-induced increases in arterial pressure (see pilot studies). Nevertheless, the ability of a PKC inhibitor to block the effects of PMA does not necessarily imply that this agent will also block the effects of ischemic PC. The results of phase B demonstrate that a dose of $5 \mathrm{mg} / \mathrm{kg}$ of chelerythrine completely inhibited the translocation of PKC $\epsilon$ and $\eta$ isoforms associated with ischemic PC in conscious rabbits (Fig. 12). To our knowledge, this is the first time that the administration of a PKC inhibitor has been shown to actually block the translocation of $\mathrm{PKC}$ isoforms after myocardial ischemia/reperfusion in vivo. Importantly, the results of phase B also demonstrate that a 10 -fold lower dose of chelerythrine $(0.5 \mathrm{mg} / \mathrm{kg})$ exerted isoform-selective effects; that is, it completely prevented the translocation of PKC $\eta$, but it failed to inhibit the translocation of PKC $\epsilon$ (Fig. 12). Thus, even within the same subgroup (novel PKCs), the response of individual isozymes to a given dose of a PKC inhibitor can differ. The isoform selectivity of the $0.5 \mathrm{mg} / \mathrm{kg}$ dose of chelerythrine is further supported by the measurements of total PKC activity. Whereas the $5 \mathrm{mg} / \mathrm{kg}$ dose decreased both calcium-stimulated and calcium-independent PKC activity (Fig. 11), implying inhibition of most or all of the PKC isozymes, the $0.5 \mathrm{mg} / \mathrm{kg}$ dose failed to decreased total PKC activity, either in the presence or in the absence of calcium (Fig. 11), suggesting that most isozymes were not inhibited. These observations should provide a useful reference for future investigations aimed at inhibiting PKC in vivo. Perhaps the most important corollary of these results is that not all $\mathrm{PKC}$ isoforms can be assumed to be affected equally by a given dose of a PKC antagonist in intact animals and that without measuring the effects of the antagonist on individual isozymes, it is impossible to ascertain which member(s) of the PKC family is/are actually inhibited in vivo.

We have recently found that the rabbit heart expresses 10 isoforms of PKC, including conventional $(\alpha, \beta, \gamma)$, novel $(\delta, \epsilon$, $\zeta, \eta$ ), and atypical $(\iota, \lambda, \mu)$ isoforms (8). Because our immunoblotting data show that the $\epsilon$ and $\eta$ isotypes are selectively translocated after ischemic PC and that chelerythrine blocks this translocation, it would be useful to measure the effect of this agent on the activity of PKC $\epsilon$ and $\eta$. Unfortunately, no assay is currently available that would permit isozyme-specific measurements of PKC activity. Calcium sensitivity has been suggested as a means of selectively assessing the activity of cPKCs. In the present study we measured PKC activity under two different conditions, that is, in the presence of calcium, PMA, and phosphatidylserine, and in the presence of PMA and phosphatidylserine only. The former measurement reflects the activity of all 10 isoforms expressed in the rabbit heart, most of which is contributed by the subgroup of cPKCs $\left(\alpha, \beta_{1}, \beta_{2}\right.$, and $\left.\gamma\right)$. However, a fraction $(<30 \%)$ of the cPKC activity is calcium independent, and $>90 \%$ of the nPKC activity and almost $100 \%$ of the aPKC activity is calcium indepen- dent $(45,47)$. Therefore, the calcium-independent PKC activity represents a composite of the activities of the nPKCs $(\delta, \epsilon$, $\zeta$, and $\eta$ ) and aPKCs $(\mathrm{l}, \lambda$, and $\mu$ ) and, to a lesser extent, of the cPKCs. It is apparent from these considerations that the calcium sensitivity of PKC activity does not allow clear-cut distinctions between one subgroup of $\mathrm{PKC}$ isotypes and another.

Role of $P K C$ in the late phase of $P C$. In a recent investigation, Ping et al. (8) demonstrated in conscious rabbits that the same PC protocol used in the present investigation (six cycles of 4-min coronary occlusion/4-min reperfusion) induces selective translocation of PKC isoforms $\epsilon$ and $\eta$ from the cytosolic to the particulate fraction, with no appreciable changes in the subcellular distribution of the other eight isoforms expressed in the rabbit heart and no changes in either total PKC activity or its subcellular distribution. However, in that study (8) it was not possible to discern whether the translocation of the $\epsilon$ and $\eta$ isoforms was a causative factor in the development of the protection or simply an epiphenomenon. Furthermore, it was not possible to distinguish which of the two isoforms was responsible for late PC. The present investigation was undertaken to resolve these issues. Our results expand those of Ping et al. (8) by demonstrating that when the translocation of both PKC $\epsilon$ and PKC $\eta$ is blocked (group X), late PC against myocardial stunning is abrogated in the same experimental model and under the same experimental conditions (group II); in contrast, when only the translocation of $\mathrm{PKC} \eta$ is inhibited whereas that of PKC $\epsilon$ is unaffected (group XI), late PC is fully manifest (group III). Thus, late PC can occur even if PKC $\eta$ fails to translocate but cannot occur if $\mathrm{PKC} \epsilon$ fails to translocate, indicating that the translocation of $\epsilon$ is necessary for the development of the protective effect, whereas that of $\eta$ is not. Based upon these findings, the present study establishes a cause-andeffect relationship between the alteration in the subcellular distribution of the PKC $\epsilon$ isozyme observed soon after ischemic PC and the attenuation of myocardial stunning observed $24 \mathrm{~h}$ later, and strongly points to $\epsilon$ as the specific PKC isoform responsible for the development of the late phase of ischemic PC.

The timing sequence of PKC activation in late PC is unknown. In principle, administration of $5 \mathrm{mg} / \mathrm{kg}$ of chelerythrine before the PC stimulus (group II) could block late PC by inhibiting PKC activity during the PC stimulus, after the PC stimulus, or both. The fact that $5 \mathrm{mg} / \mathrm{kg}$ of chelerythrine blocked late PC when given 5 min before the PC stimulus (group II) but failed to do so when given 10 min after the PC stimulus (group IV) indicates that the critical PKC-mediated signaling events responsible for the development of late PC must occur during the six occlusion/reperfusion cycles or shortly thereafter (within the first $10 \mathrm{~min}$ of reperfusion). Once these events have taken place, administration of PKC inhibitors has no effect on the development of the PC phenomenon. The results obtained in our model of late PC differ from those obtained in previous studies in models of early PC, which have shown that the activation of PKC is not necessary to trigger the protection in isolated rabbit myocytes (48) and in isolated rabbit hearts (49). In one of these studies (49), Yang et al. demonstrated that the infarct-sparing effect was blocked when the PKC inhibitor staurosporine was present during the second (sustained) ischemic insult but not when it was present during or immediately after the initial ischemic PC stimulus, indicating that the activity of $\mathrm{PKC}$ is required to mediate the protection but not to put the heart into a preconditioned state. 
Because of the extensive differences between these previous studies $(48,49)$ and the present investigation (early PC versus late PC; PC against lethal injury versus PC against stunning; different experimental preparations), a direct comparison is not possible. Because the cellular and molecular mechanisms responsible for the two phases of ischemic $\mathrm{PC}$ are likely to be different, it is conceivable that the PKC-mediated signaling events underlying early and late $\mathrm{PC}$ may also be different. For example, unlike early PC, late PC appears to involve changes in gene expression (50); if this is indeed the case, then late PC (but not early PC) would be the result of the activation of distinctive signal transduction pathways that control the synthesis of cardioprotective proteins.

Only one previous investigation (5) has examined the effect of PKC inhibitors on the late phase of PC. In this study (5), Baxter et al. subjected open-chest rabbits to ischemic PC with four cycles of 5-min coronary occlusion/10-min reperfusion; this protocol resulted in a decrease in infarct size $24 \mathrm{~h}$ later, which was prevented by the administration of chelerythrine $(5 \mathrm{mg} / \mathrm{kg})$ before the PC ischemia. The present study extends the findings of Baxter et al. by demonstrating $(a)$ that chelerythrine abrogates late PC against myocardial stunning, (b) that this effect correlates with the translocation of PKC $\epsilon$ but not with that of PKC $\eta$, and $(c)$ that chelerythrine exerts these effects in a conscious animal preparation. Taken together with the results of Baxter et al. (5) and Ping et al. (8), the present results support a major pathophysiological role of $\mathrm{PKC}$ in the late phase of ischemic $\mathrm{PC}$, both in the protection against myocardial stunning and in the protection against myocardial infarction. Because neither ischemic PC nor chelerythrine had any effect on the subcellular distribution of PKC isoforms $\alpha, \beta_{1}, \beta_{2}, \gamma, \delta, \zeta, \iota, \lambda$, and $\mu$, and because the cardioprotection was unrelated to the subcellular distribution of the $\eta$ isotype, the present study suggests for the first time that late $\mathrm{PC}$ against stunning is dependent upon the activation of one individual $\mathrm{PKC}$ isoform (PKC $\epsilon$ ).

Role of PKC in the early phase of PC. There currently exists controversy regarding the role of $\mathrm{PKC}$ in the early phase of ischemic PC against infarction. Downey's group was the first to propose the hypothesis that activation of PKC plays a key role in the development of early PC against infarction (18-20). The PKC hypothesis of early PC has been supported by numerous investigations, which have demonstrated that various PKC blockers (i.e., H-7, staurosporine, chelerythrine, polymixin B) attenuate the protective effects of ischemic PC whereas PKC activators (i.e., PMA and 1-oleoyl 2-acetyl glycerol) mimic this protective effect in rabbits $(23,27-29)$, rats $(21,24,25,30,33)$, dogs (31), and isolated rabbit cardiomyocyte preparations $(22,32)$ as well as in isolated human atrial trabeculae (26). However, in contrast to the above studies, others have found that PKC inhibitors (H-7, staurosporine, bisindolylmaleimide, polymixin B) fail to block the protective effect of ischemic PC in dogs (35) and pigs $(36,37)$. The reason(s) for these discrepant results is unknown.

One possible explanation is that the critical PKC isoform(s) responsible for PC may not have been consistently inhibited in the aforementioned studies, because the ability of the inhibitors to block PKC activation was not assessed. The PKC family includes at least 11 isoforms, 10 of which are expressed in rabbit myocardium (8). Given the fact that only two of these isoforms $(\epsilon$ and $\eta)$ appear to be activated during ischemic PC (as indicated by our previous [8] and present data), and that translocation of only one isoform (PKC $\epsilon$ ) appears to be necessary for late PC against stunning (as indicated by the present data), it is conceivable that a given dose of a PKC inhibitor might block the noncritical isoforms but not the isoforms that are crucial to the development of ischemic PC. The present study provides direct evidence in support of this hypothesis. The results obtained with $0.5 \mathrm{mg} / \mathrm{kg}$ of chelerythrine demonstrate that a PKC antagonist can have isoform-selective effects in vivo; that is, the drug can be given at a dose that inhibits some PKC isotypes (e.g., ๆ) without affecting the isotype that is critical for late $\mathrm{PC}(\mathrm{PKC} \epsilon)$. Without direct measurements of isoform distribution, it would be problematic to predict the effects of PKC inhibitors on individual isotypes in vivo, also because the pharmacokinetics of these agents and the actual concentrations they achieve in the interstitial or intracellular space in intact animals are unknown. These considerations emphasize the importance of correlating the effect of a PKC inhibitor on PC with its effect on individual PKC isoforms in vivo.

Conclusions. In summary, this study expands our understanding of the mechanism of late PC against myocardial stunning by demonstrating that PKC activation is an essential step in the development of this phenomenon in conscious rabbits. Taken together with previous studies suggesting an involvement of PKC in early and late PC against myocardial infarction $(5,18-21,23-25,27-31,33)$, the present results support a central role of this family of enzymes in the myocardial adaptation to brief ischemic stresses. Our study takes this analysis a step further by providing direct evidence that the signaling pathway responsible for the late phase of ischemic PC involves specifically one PKC isoform (the $\epsilon$ isoform) among the 10 $\mathrm{PKC}$ isotypes that are expressed in the adult rabbit heart. Thus, the PKC-mediated signaling that underlies ischemic PC (or at least its late phase) appears to be extremely isoformselective. The present findings should help to focus future research on the $\epsilon$ isozyme. The notion that PKC $\epsilon$ plays a key role in ischemic PC would provide a rationale for developing therapies aimed at activating selectively either this protein or its downstream target(s).

\section{Acknowledgments}

We gratefully acknowledge Gregg Shirk for expert technical assistance and Trudy Keith for expert secretarial assistance.

This study was supported in part by National Institutes of Health (NIH) grants R01 HL-43151 and HL-55757 (R. Bolli), by NIH grant R29 HL-58166 and National American Heart Association (AHA) grant 9750721 N (P. Ping), by Kentucky AHA Affiliate grants KY-96GB-32 (Y. Qiu) and KY-96-GB-31 (X.-L. Tang), and by the Medical Research Grant Program of the Jewish Hospital Research Foundation, Louisville, KY.

\section{References}

1. Kuzuya, T., S. Hoshida, N. Yamashita, H. Fuji, H. Oe, M. Hori, N. Taniguchi, T. Kamada, and M. Tada. 1993. Delayed effects of sublethal ischemia on the acquisition of tolerance to ischemia and myocardial antioxidant enzymes. Circ. Res. 72:1293-1299.

2. Marber, M.S., D.S. Latchman, J.M. Walker, and D.M. Yellon. 1993. Cardiac stress protein elevation 24 hours after brief ischemia or heat stress is associated with resistance to myocardial infarction. Circulation. 88:1264-1272.

3. Baxter, G.F., M.S. Marber, V.C. Patel, and D.M. Yellon. 1994. Adenosine receptor involvement in a delayed phase of myocardial protection 24 hours after ischemic preconditioning. Circulation. 90:2993-3000.

4. Sun, J.Z., X.L. Tang, A.A. Knowlton, S.W. Park, Y. Qiu, and R. Bolli. 
1995. Late preconditioning against myocardial stunning. An endogenous protective mechanism that confers resistance to postischemic dysfunction $24 \mathrm{~h}$ after brief ischemia in conscious pigs. J. Clin. Invest. 95:388-403.

5. Baxter, G.F., F.M. Goma, and D.M. Yellon. 1995. Involvement of protein kinase $\mathrm{C}$ in the delayed cytoprotection following sublethal ischaemia in rabbit myocardium. Br. J. Pharmacol. 115:222-224.

6. Tang, X.L., Y. Qiu, S.W. Park, J.Z. Sun, A. Kalya, and R. Bolli. 1996. Time-course of late preconditioning against myocardial stunning in conscious pigs. Circ. Res. 79:424-434.

7. Sun, J.Z., X.L. Tang, S.W. Park, Y. Qiu, J.F. Turrens, and R. Bolli. 1996. Evidence for an essential role of reactive oxygen species in the genesis of late preconditioning against myocardial stunning in conscious pigs. J. Clin. Invest. 97:562-576.

8. Ping, P., J. Zhang, Y. Qiu, X.L. Tang, S. Manchikalapudi, X. Cao, and R. Bolli. 1997. Ischemic preconditioning induces selective translocation of protein kinase $\mathrm{C}$ isoforms $\epsilon$ and $\eta$ in the heart of conscious rabbits without subcellular redistribution of total protein kinase C activity. Circ. Res. 81:404-414.

9. Yang, X.M., G.F. Baxter, R.J. Heads, D.M. Yellon, J.M. Downey, and M.V. Cohen. 1996. Infarct limitation of the second window of protection in a conscious rabbit model. Cardiovasc. Res. 31:777-783.

10. Bolli, R., Z.A. Bhatti, X.L. Tang, Y. Qiu, Q. Zhang, Y. Guo, and A.K. Jadoon. 1997. Evidence that late preconditioning against myocardial stunning in conscious rabbits is triggered by the generation of nitric oxide. Circ. Res. 81: $42-52$.

11. Maldonado, C., Y. Qiu, X.L. Tang, M.V. Cohen, J. Auchampach, and R. Bolli. 1997. Role of adenosine receptors in late preconditioning against myocardial stunning in conscious rabbits. Am. J. Physiol. 273:H1324-H1332.

12. Baxter, G.F., F.M. Goma, and D.M. Yellon. 1997. Characterization of the infarct-limiting effect of delayed preconditioning: timecourse and dosedependency studies in rabbit myocardium. Basic Res. Cardiol. 92:159-167.

13. Qiu, Y., A. Rizvi, X.L. Tang, S. Manchikalapudi, H. Takano, A.K. Jadoon, W.J. Wu, and R. Bolli. 1997. Nitric oxide triggers late preconditioning against myocardial infarction in conscious rabbits. Am. J. Physiol. 273:H2931H2936.

14. Bolli, R., S. Manchikalapudi, X.L. Tang, H. Takano, Y. Qiu, Y. Guo, Q. Zhang, and A.K. Jadoon. 1997. The protective effects of late preconditioning against myocardial stunning in conscious rabbits are mediated by nitric oxide synthase: evidence that nitric oxide acts both as a trigger and as a mediator of the late phase of ischemic preconditioning. Circ. Res. 81:1094-1107.

15. Takano, H., S. Manchikalapudi, X.L. Tang, Y. Qiu, A. Rizvi, A.K. Jadoon, Q. Zhang, and R. Bolli. 1998. Nitric oxide synthase is the mediator of late preconditioning against myocardial infarction in conscious rabbits. Circulation. In press.

16. Cohen, M.V., and J.M. Downey. 1995. Preconditioning during ischemia. Cardiol. Rev. 3:137-149.

17. Strasser, R.H., R. Braun-Dullaeus, H. Walendzik, and R. Marquetant. 1992. $\alpha_{1}$-Receptor-independent activation of protein kinase $\mathrm{C}$ in acute myocardial ischemia. Mechanisms for sensitization of the adenylyl cyclase system. Circ. Res. 70:1304-1312.

18. Liu, Y., M.V. Cohen, and J.M. Downey. 1994. Chelerythrine, a highly selective protein kinase $\mathrm{C}$ inhibitor, blocks the anti infarct effect of ischemic preconditioning in rabbit hearts. Cardiovasc. Drugs Ther. 8:881-882.

19. Liu, Y., K. Ytrehus, and J.M. Downey. 1994. Evidence that translocation of protein kinase $\mathrm{C}$ is a key event during ischemic preconditioning of rabbit myocardium. J. Mol. Cell Cardiol. 26:661-668.

20. Ytrehus, K., Y. Liu, and J.M. Downey. 1994. Preconditioning protects ischemic rabbit heart by protein kinase C activation. Am. J. Physiol. 266: H1145-H1152.

21. Speechly-Dick, M.E., M.M. Mocanu, and D.M. Yellon. 1994. Protein kinase C: its role in ischemic preconditioning in the rat. Circ. Res. 75:586-590.

22. Armstrong, S., and C.E. Ganote. 1994. Preconditioning of isolated rabbit cardiomyocytes: effects of glycolytic blockade, phorbol esters, and ischaemia. Cardiovasc. Res. 28:1700-1706.

23. Tsuchida, A., Y. Liu, G.S. Liu, M.V. Cohen, and J.M. Downey. 1994. $\alpha_{1}$ adrenergic agonists precondition rabbit ischemic myocardium independent of adenosine by direct activation of protein kinase C. Circ. Res. 75:576-584.

24. Mitchell, M.B., X. Meng, L. Ao, J.M. Brown, A.H. Harken, and A. Banerjee. 1995. Preconditioning of isolated rat heart is mediated by protein kinase C. Circ. Res. 76:73-81.

25. Li, Y., and R.A. Kloner. 1995. Does protein kinase C play a role in ischemic preconditioning in rat hearts? Am. J. Physiol. 268:H426-H431.

26. Speechly-Dick, M.E., G.J. Grover, and D.M. Yellon. 1995. Does ischemic preconditioning in the human involve protein kinase $\mathrm{C}$ and the ATPdependent $\mathrm{K}^{+}$channel? Studies of contractile function after simulated ischemia in an atrial in vitro model. Circ. Res. 77:1030-1035.
27. Sakamoto, J., T. Miura, M. Goto, and O. Iimura. 1995. Limitation of myocardial infarct size by adenosine $\mathrm{A}_{1}$ receptor activation is abolished by protein kinase $C$ inhibitors in the rabbit. Cardiovasc. Res. 29:682-688.

28. Goto, M., Y. Liu, X.M. Yang, J.L. Ardell, M.V. Cohen, and J.M. Downey. 1995. Role of bradykinin in protection of ischemic preconditioning in rabbit hearts. Circ. Res. 77:611-621.

29. Liu, Y., A. Tsuchida, M.V. Cohen, and J.M. Downey. 1995. Pretreatment with angiotensin II activates protein kinase $\mathrm{C}$ and limits myocardial infarction in isolated rabbit hearts. J. Mol. Cell Cardiol. 27:883-892.

30. Brew, E.C., M.B. Mitchell, T.F. Rehring, F. Gamboni-Robertson, R.C. McIntyre, Jr., A.H. Harken, and A. Banerjee. 1995. Role of bradykinin in cardiac functional protection after global ischemia-reperfusion in rat heart. Am. J. Physiol. 269:H1370-H1378.

31. Kitakaze, M., K. Node, T. Minamino, K. Komamura, H. Funaya, Y. Shinozaki, M. Chujo, H. Mori, H. Inoue, M. Hori, and T. Kamada. 1996. Role of activation of protein kinase $\mathrm{C}$ in the infarct size-limiting effect of ischemic preconditioning through activation of ecto-5'-nucleotidase. Circulation. 93:781-791.

32. Armstrong, S.C., and C.E. Ganote. 1996. Preconditioning of isolated rabbit cardiomyocytes: induction by metabolic stress and blockade by the adenosine antagonist SPT and calphostin C, a protein kinase $\mathrm{C}$ inhibitor. Cardiovasc. Res. 28:72-77.

33. Rehring, T.F., R.S. Randall, J.C. Cleveland, X. Meng, F.S. GamboniRobertson, A.H. Harken, and A. Banerjee. 1996. Alpha-adrenergic preservation of myocardial pH during ischemia is PKC isoform dependent. J. Surg. Res. 63:324-327.

34. Steinberg, S.F., M. Goldberg, and V.O. Rybin. 1995. Protein kinase C isoform diversity in the heart. J. Mol. Cell Cardiol. 27:141-153.

35. Przyklenk, K., M.A. Sussman, B.Z. Simkhovich, and R.A. Kloner. 1995. Does ischemic preconditioning trigger translocation of protein kinase $\mathrm{C}$ in the canine model? Circulation. 92:1546-1557.

36. Vahlhaus, C., R. Schulz, H. Post, R. Onallah, and G. Heusch. 1996. No prevention of ischemic preconditioning by the protein kinase $\mathrm{C}$ inhibitor staurosporine in swine. Circ. Res. 79:407-414.

37. Vogt, A., M. Barancik, D. Weihrauch, M. Arras, T. Podzuweit, and W. Schaper. 1994. Protein kinase C inhibitors reduce infarct size in pig hearts in vivo. Circulation. 90(Suppl. I):I-647. (Abstr.)

38. Simkhovich, B.Z., K. Przyklenk, S.L. Hale, M. Patterson, and R.A Kloner. 1996. Direct evidence that ischemic preconditioning does not cause PKC translocation in rabbit heart. Cardiovasc. Res. 32:1064-1070.

39. Li, X.Y., P.B. McCay, M. Zughaib, M.O. Jeroudi, J.F. Triana, and R. Bolli. 1993. Demonstration of free radical generation in the "stunned" myocardium in the conscious dog and identification of major differences between conscious and open-chest dogs. J. Clin. Invest. 92:1025-1041.

40. Triana, J.F., X.Y. Li, U. Jamaluddin, J.I. Thornby, and R. Bolli. 1991. Postischemic myocardial "stunning": identification of major differences between the open-chest and the conscious dog and evaluation of the oxygen radical hypothesis in the conscious dog. Circ. Res. 69:731-747.

41. Cohen, M.V., X.M. Yang, and J.M. Downey. 1994. Conscious rabbits become tolerant to multiple episodes of ischemic preconditioning. Circ. Res. 74: 998-1004

42. Burckhartt, B., X.M. Yang, A. Tsuchida, K.M. Mullane, J.M. Downey, and M.V. Cohen. 1995. Acadesine extends the window of protection afforded by ischemic preconditioning in conscious rabbits. Cardiovasc. Res. 29:653-657.

43. Haessler, R., K. Kuzume, G.L. Chien, R.A. Wolff, R.F. Davis, and D.M Van Winkle. 1994. Anaesthetics alter the magnitude of infarct limitation by ischaemic preconditioning. Cardiovasc. Res. 28:1574-1580.

44. Schwartz, L.M., R.B. Jennings, and K.A. Reimer. 1997. Premedication with the opioid analgesic butorphanol raises the threshold for ischemic preconditioning in dogs. Basic Res. Cardiol. 92:106-114.

45. Newton, A.C. 1995. Protein kinase C: structure, function, and regulation. Biochem. J. 270:28495-28498.

46. Herbert, J.M., J.M. Augereau, J. Gleye, and J.P. Maffrand. 1990. Chelerythrine is a potent and specific inhibitor of protein kinase C. Biochem. Biophys. Res. Commun. 172:993-999.

47. Kaibuchi, K., Y. Fukumoto, N. Oku, Y. Takai, K. Arai, and M. Muramatsu. 1989. Molecular genetic analysis of the regulatory and catalytic domains of protein kinase C. J. Biol. Chem. 264:13489-13496.

48. Armstrong, S.C., D.B. Hoover, M.H. Delacey, and C.E. Ganote. 1996. Translocation of PKC, protein phosphatase inhibition and preconditioning of rabbit cardiomyocytes. J. Mol. Cell Cardiol. 28:1479-1492.

49. Yang, X.M., H. Sato, J.M. Downey, and M.V. Cohen. 1997. Protection of ischemic preconditioning is dependent upon a critical timing sequence of protein kinase C activation. J. Mol. Cell Cardiol. 29:991-999.

50. Marber, M.S., and D.M. Yellon. 1996. Myocardial adaptation, stress proteins, and the second window of protection. Ann. NY Acad. Sci. 793:123-141. 